Document downloaded from:

http://hdl.handle.net/10251/119990

This paper must be cited as:

Alemany Díaz, MDM.; Ortiz Bas, A.; Fuertes-Miquel, VS. (2018). A decision support tool for the order promising process with product homogeneity requirements in hybrid Make-ToStock and Make-To-Order environments. Application to a ceramic tile company. Computers \& Industrial Engineering. 122:219-234. https://doi.org/10.1016/j.cie.2018.05.040

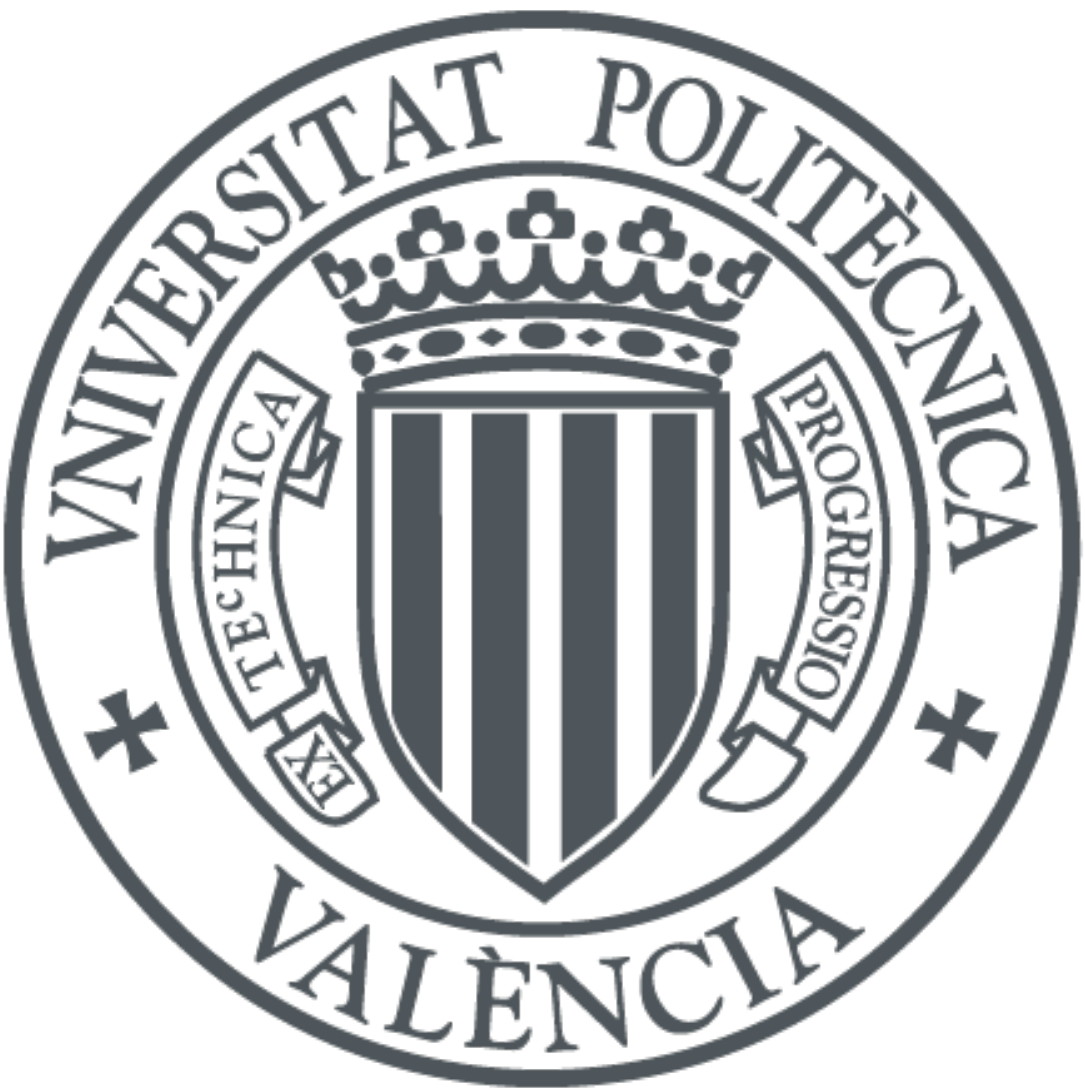

The final publication is available at

http://doi.org/10.1016/j.cie.2018.05.040

Copyright Elsevier

Additional Information 


\section{Accepted Manuscript}

A decision support tool for the order promising process with product homogeneity requirements in hybrid Make-To-Stock and Make-To-Order environments. Application to a ceramic tile company

M.M.E Alemany, A. Ortiz, V.S. Fuertes-Miquel, Ángel Ortiz Bas, Vicente S. Fuertes-Miquel

PII:

DOI:

Reference:

To appear in:

Received Date:

Revised Date:

Accepted Date:
S0360-8352(18)30249-3

https://doi.org/10.1016/j.cie.2018.05.040

CAIE 5246

Computers \& Industrial Engineering

14 May 2018

25 May 2018

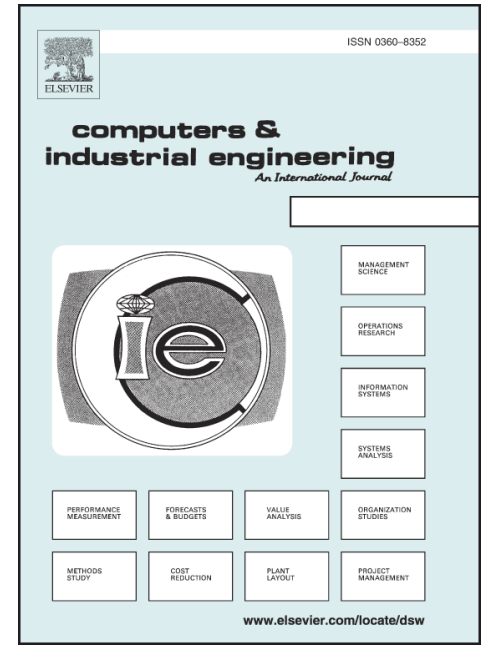

Please cite this article as: Alemany, M.M.E, Ortiz, A., Fuertes-Miquel, V.S., Ortiz Bas, A., Fuertes-Miquel, V.S., A decision support tool for the order promising process with product homogeneity requirements in hybrid MakeTo-Stock and Make-To-Order environments. Application to a ceramic tile company, Computers \& Industrial Engineering (2018), doi: https://doi.org/10.1016/j.cie.2018.05.040

This is a PDF file of an unedited manuscript that has been accepted for publication. As a service to our customers we are providing this early version of the manuscript. The manuscript will undergo copyediting, typesetting, and review of the resulting proof before it is published in its final form. Please note that during the production process errors may be discovered which could affect the content, and all legal disclaimers that apply to the journal pertain. 
A decision support tool for the order promising process with product homogeneity requirements in hybrid Make To Stock and Make To Order environments. Application to a ceramic tile company

M.M.E Alemany, A. Ortiz, V.S. Fuertes-Miquel

María del Mar Eva Alemany (corresponding autor)

Research Centre on Production Management and Engineering (CIGIP),

Universitat Politècnica de València, Camino de Vera S/N, 46022, Valencia, Spain

Phone: +34 963877007 ext.: 76868

E-mail: mareva@omp.upv.es

\section{Ángel Ortiz Bas}

Research Centre on Production Management and Engineering (CIGIP),

Universitat Politècnica de València, Camino de Vera S/N, 46022, Valencia, Spain

Phone: +34963877007 ext.: 77061

E-mail: aortiz@cigip.upv.es

\section{Vicente S. Fuertes-Miquel}

Departamento de Ingeniería Hidráulica y Medio Ambiente,

Universitat Politècnica de València, Camino de Vera S/N, 46022, Valencia, Spain

Phone: +34 963877007 ext.: 86103

E-mail:vfuertes@upv.es 


\title{
A decision support tool for the order promising process with product homogeneity requirements in hybrid Make-To-Stock and Make-To-Order environments. Application to a ceramic tile company
}

\begin{abstract}
Order promising in manufacturing systems that produce non-uniform units of the same finished good becomes a more complex process when customer orders need to be served with homogeneous units. To facilitate this task, we propose a mathematical model-based decision tool to support the order promising process according to product homogeneity requirements in hybrid Make-To-Stock (MTS) and Make-To-Order (MTO) contexts. In these manufacturing environments, the comparison of Available-To-Promise (ATP) and/or Capable-To-Promise (CTP) quantities with homogeneous ones ordered by customers is necessary during the order commitment. To properly deal with customers' product uniformity requirements, different ATP consumption rules are implemented by defining a novel objective function. CTP modelling in these systems also entails having to address new aspects, such as estimating future homogeneous quantities in additional lots to the master plan, accomplishing minimum lot sizes and saving in setups when programming new lots. By including CTP in the order promising model, a closer integration with the master production schedule is achieved. The resulting mathematical model was applied to a ceramic tile company in different supply scenarios and execution modes, and at several availability levels (ATP and ATP\&CTP). The results validate model performance and provide insights into the impact of ATP consumption rules on the profits made from committed customer orders in different scenarios for the specific ceramic tile company.
\end{abstract}

Keywords: available-to-promise; capable-to-promise; order promising process; customer homogeneity requirement; hybrid MTS-MTO; mixed integer linear programming

\section{Introduction}

Competitive pressures force companies to continuously devise ways to achieve better supply chain solutions; that is, faster-better-cheaper. One key area is overall customer satisfaction (Makatsoris, Chang \& Richards, 2004) that comprises several dimensions, such as rapid response to customer needs, reliability of commitments, short delivery times and high customer service levels (Alemany et al., 2015). They all are strongly affected by the order promising process (OPP) that can be defined as a set of activities done to analyse the extent to which it is possible to be committed with a customer based on the order proposal received by the company (Alemany, Alarcón, Ortiz \& Lario, 2008). Different authors consider the OPP a 
highly critical task that impacts customer service levels (Fleischmann \& Meyr, 2004) and customer satisfaction (Okongwu, Lauras, Dupont \& Humez, 2012).

Several techniques support the OPP and depend mainly on the manufacturing strategy followed by the company. Along these lines, for the Make-To-Stock (MTS) production strategy, the OPP is based on available-to-promise (ATP). Fleischmann \& Meyr (2004) define ATP as either the stocks on hand or the projected inflows of items stocked at the customer order decoupling point (master plan) that have not yet been allocated to specific orders, and can thus be promised to customers in the future. The capable-to-promise (CTP) technique confers availability checks functionality if the result of the latter is negative and production is required (Zshorn, 2006) for MTS products or new production lots should be scheduled for Make-To-Order (MTO) and Assemble-To-Order (ATO) products. Hence ATP may be linked to existing products, while CTP relates to the capacity to produce (Framinan \& Leisten, 2009). However, CTP is often included in ATP functionalities (Kilger \& Schneeweiss, 2000). The use of CTP availability when promising orders implies essential master production schedule (MPS) modifications to properly deal with the dynamic interactions between the OPP and the MPS.

In the global market place, companies are obliged to work in accordance with distinct production strategies. For these companies, OPP complexity substantially increases because different availability levels (ATP \& CTP) should be simultaneously managed. Kalantari, Rabbani and Ebadian (2011) emphasise that the number of research works on hybrid MTS\&MTO systems as regards order acceptance/rejection is insignificant. Volling and Spengler (2011) state that work on the subject of the OPP, the MPS and their dynamic interaction is very limited.

Furthermore, OPP complexity is higher for companies with lack of homogeneity in the product (LHP) characterized by producing non-homogeneous units of the same FG due to the non-uniformity of raw materials and/or the characteristics of productive processes. Examples of LHP companies can be found in sectors such as: the semiconductor manufacturing industry (Han, Dong \& Liu, 2014), ceramics, horticulture, textiles, wood, marble, tanned hides and leather goods. As customers require homogeneous units in their orders, companies with LHP are obliged to include sorting stages to separate lots into homogeneous sublots. The result is a classification of FGs into subtypes, that is: units of the same FG with different characteristics that are relevant for customers (e.g. fruit variety with the same quality, weight and size). 
The additional difficulty for the OPP in LHP companies stems from the fact that customers need to be served with homogeneous units of the same FG. Homogeneity customer specification and the existence of several subtypes of the same FG in LHP environments complicate the OPP because alternatives for allocating quantities of available-to-promise subtypes (ATP-LHP) to customer orders substantially increases, and the homogeneity requirement complicates the search for a feasible and optimal solution. Furthermore, during the OPP, the real homogeneous quantities available of the same FG to be promised to customers in planned production lots are subject to uncertainty (Grillo, Alemany \& Ortiz, 2016), and are not known until their production is finished and classified. Therefore, in hybrid MTS\&MTO for both ATP and CTP, an accurate estimation of future homogeneous quantities should be made (ATP\&CTP-LHP) to avoid not fulfilling the homogeneity, quantity and duedate conditions required by customers.

In view of the above, the objective of this paper is to develop a decision support tool for the OPP with product homogeneity requirements in hybrid MTS\&MTO contexts. In doing so, different aspects were addressed which, at the same time, constitute the novelties of this research work. The contribution of this paper is, therefore, manifold:

- Firstly, special characteristics that derive from LHP industries define a new OPP problem whose modelling is a contribution

- Secondly, by properly dealing with product uniformity customer requirements, different ATP consumption rules were implemented that impact a company's global profit by defining a novel objective function that combines two objectives by the weighted sum method (Marler \& Arora, 2010)

- Thirdly, our approach shows how master planning and order promising can be more closely integrated into a unique model because common resources are shared for the production of MTS \& MTO FGs. The inclusion of CTP-LHP in the ATP-LHP model, along with setups and minimum lot sizes for FGs and product families in production lines, converts the problem into a capacitated lot-sizing and loading problem (CLSLP) (Özdamar \& Birbil, 1998)

- Finally, we provide a methodology to integrate the master planning and the OPP into a dynamic environment for hybrid MTS\&MTO production systems with LHP.

The remainder of the paper is organised as follows. Section 2 presents a literature review on the OPP models that are relevant to the problem under study. Section 3 describes 
the LHP problem characteristics to be addressed. Section 4 formulates the mixed integer programming model by emphasising the main differences with existing models. The methodology describing the OPP dynamism and its interaction with the MPS is detailed in Section 5. Section 6 provides details of the developed numerical study to validate the model, evaluates the consumption rules and discusses the results. Finally, Section 7 reports the significance of using the model and the ATP allocation rules, as well as future research directions.

\section{Literature review}

There is a rich literature body about OPP models. In order to focus only on relevant research, firstly the problem under study was formally stated and, accordingly, a literature review was carried out. The problem is to provide a response to customer order proposals about their acceptance or rejection in companies with LHP manufacturing MTS\&MTO products that share common resources. LHP companies are characterized by manufacturing nonhomogeneous units of the same product, which are classified into subtypes based on the attributes that are relevant for customers. As customer orders need to be served with homogeneous units of the same product (the same subtype), these companies must also decide about: 1) the allocation of existing uncommitted homogeneous quantities (ATP-LHP) for orders with MTS products; 2) the schedule of new production lots in the master plan for orders requesting MTO products or for MTS products for which not enough ATP-LHP is available, as long as uncommitted capacity exists when considering the homogeneity of customer requirements (CTP-LHP).

As regards ATP and CTP for LHP contexts, if customers do not specify the subtype that they require in their orders (e.g. ceramic tiles with the same tone and gage, regardless of specific tone and gage), defining the ATP-LHP in terms of subsets of homogeneous quantities without identifying their subtype suffices. Otherwise, the specific subtype should be estimated and defined for ATP-LHP quantities. For both cases, discrete non-homogeneous ATP-LHP quantities of different subtypes cannot be mixed to serve the same order. This means that the choice of booking ATP-LHP from a specific homogeneous subset of a FG can affect subsequent promises, and defining ATP-LHP allocation rules to customer orders is necessary. In relation to CTP, if the quantities produced by different resources are not likely to be 
homogeneous, the available uncommitted capacity should be expressed for all these particular resources (e.g., production lines for ceramic companies or fields for fruit). Therefore, homogeneous quantities in the additional lots scheduled, and either expressed or not in subtype terms, based on the CTP should be estimated (CTP-LHP).

In the literature methods for ATP calculation and consumption can be found in Fogarty, Blackstone and Hoffmann (1991). Kilger and Meyr (2008) affirm that ATP is expressed in terms of items storage at the decoupling point: finished goods in MTS, components in ATO and raw materials in MTO. Besides ATO and MTO companies checking the ATP of items at the decoupling point, they need to check if there is enough uncommitted production capacity (CTP) for either assembly or producing FG, respectively, to fulfil customer orders. It is possible to make capacity checks (CTP) in either an aggregate capacity model or a detailed manner by finite capacity scheduling (Steger-Jensen \& Svensson, 2004), although the latter often yields lengthy computations and, therefore, longer response times to customer requests (Quante \& Meyr, 2009). To reduce computational times, some OPP solution approaches exist that are based on heuristics (Akkan, 2015) and meta-heuristics, such as tabu search (Cesaret, Oğuz, Sibel \& Salman, 2012) or genetic algorithms (Rom \& Slotnick, 2009). None of these ATP and CTP calculation methods considers that homogeneity aspects are necessary in the LHP context. Besides, there is a very limited number of OPP models available in the literature for combining ATP and CTP availabilities for pure MTS or mixed MTS\&MTO production environments, and for dealing with the interaction between the OPP and the MPS.

Table 1 shows the analysis of the relevant research for this work, in order to better show our contribution in terms of the type of model/work proposed, customers' requirement of homogeneity, the type of products promised, the availability levels checked, the way to combine them, the CTP modelling characteristics, if an OPP\&MPS integration is made in a rolling horizon (dynamic) or not (static), and if it is explicitly described.

As shown in Table 1, the only works that deal with LHP during the OPP are those of Alemany, Grillo, Ortiz and Fuertes (2015) and Grillo, Alemany and Ortiz (2017). These papers propose an MILP model for the OPP in companies with LHP, ceramic and fruit, respectively, where customers need to be served with homogeneous quantities. Although they both calculate ATP-LHP quantities to commit orders, only the second one specifies the 
subtype (quality, harvesting date, etc.). The perishability aspect of fruit is also modelled. Nevertheless, both papers assume a pure MTS strategy and do not allow additional quantities to be scheduled using CTP. Therefore, they do not allow the MPS to be modified, which is one of the contributions of our paper.

\begin{tabular}{|c|c|c|c|c|c|c|c|c|c|c|c|c|c|c|c|c|c|}
\hline \multirow{2}{*}{ REFERENCES } & \multirow{2}{*}{$\begin{array}{c}\text { TYPE OF } \\
\text { MODEL/WORK }\end{array}$} & \multicolumn{2}{|c|}{\begin{tabular}{|c} 
HOMOGE \\
NEITY \\
REQUIRED
\end{tabular}} & \multicolumn{2}{|c|}{$\begin{array}{c}\text { TYPE OF } \\
\text { PRODUCTS }\end{array}$} & \multicolumn{4}{|c|}{ AVAILABILITY LEVELS } & \multicolumn{2}{|c|}{$\begin{array}{c}\text { ATP\& CTP } \\
\text { AVAILABILITY } \\
\text { CHECK }\end{array}$} & \multicolumn{3}{|c|}{ CTP MODELLING } & \multicolumn{3}{|c|}{ MPS MODIFICATION } \\
\hline & & YES & No & $\begin{array}{l}\text { MTS/ } \\
\text { BTS }\end{array}$ & $\begin{array}{c}\text { MTO/ } \\
\text { вто }\end{array}$ & ATP & СТP & $\begin{array}{l}\text { ATP- } \\
\text { LHP }\end{array}$ & $\begin{array}{l}\text { CTP- } \\
\text { LHP }\end{array}$ & $\begin{array}{c}\text { Sequential/ } \\
\text { Independ }\end{array}$ & Jointly & $\begin{array}{c}\text { Extra } \\
\text { capacity }\end{array}$ & Setups & $\begin{array}{c}\text { Minimum } \\
\text { Lot Size }\end{array}$ & Static & Dynamic & $\begin{array}{l}\text { Explicitly } \\
\text { Described }\end{array}$ \\
\hline Alemany et al. (2015) & MILP & $\mathrm{x}$ & & $\mathrm{x}$ & & & & $\mathrm{x}$ & & & & & & & $\overline{5}$ & & \\
\hline Grillo et al. (2017) & MILP & $\mathrm{x}$ & & $\mathrm{x}$ & & & & $\mathrm{x}$ & & & & & & $\bar{B}$ & 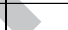 & & \\
\hline Makatsoris et al. (2004) & Architecture & & $\mathrm{x}$ & $\mathrm{x}$ & & $x$ & $x$ & & & $x$ & & & & 4 & $\mathrm{x}$ & & \\
\hline Christou and Ponis (2009) & MILP & & $\mathrm{x}$ & $\mathrm{x}$ & & $x$ & $x$ & & & $\mathrm{x}$ & & $x$ & & & $x$ & & \\
\hline Brabazon and MacCarthy (2006) & Simulation & & $\mathrm{x}$ & $\mathrm{x}$ & & $\mathrm{x}$ & $\mathrm{x}$ & & & $\mathrm{x}$ & & & 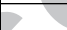 & & & & \\
\hline Brabazon and MacCarthy (2010) & Markov & & $\mathrm{x}$ & $x$ & & $x$ & $x$ & & & $x$ & & & & & & & \\
\hline Robison and Carlson (2007) & MILP & & $\mathrm{x}$ & $x$ & $x$ & $x$ & $\mathrm{x}$ & & & & $x$ & & 7 & & $x$ & & \\
\hline Kalantari et al. (2011) & DSS/MILP & & $\mathrm{x}$ & $\mathrm{x}$ & $\mathrm{x}$ & $\mathrm{x}$ & $\mathrm{x}$ & & & $\mathrm{x}$ & 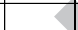 & $\mathrm{x}$ & 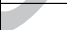 & & $\mathrm{x}$ & & \\
\hline Dumetz et al. (2016) & Simulation & & $\mathrm{x}$ & $x$ & $x$ & $x$ & $x$ & & & $x$ & & 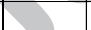 & & & & & \\
\hline Volling et al. (2013) & Review & & $\mathrm{x}$ & $x$ & $\mathrm{x}$ & $x$ & $x$ & & & $\mathrm{x}$ & 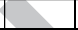 & $D$ & & & & & \\
\hline Volling and Spengler (2011) & MILP & & $\mathrm{x}$ & & $x$ & & $x$ & & & 8 & 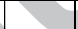 & $x$ & & & & $x$ & $x$ \\
\hline This paper & MILP/Methodology & $x$ & & $x$ & $x$ & & & $x$ & $x$ & & $x$ & $x$ & $x$ & $x$ & & $x$ & $x$ \\
\hline
\end{tabular}

Table 1. Analysis of the relevant literature for this research

Research into the OPP for only MTS products, based on ATP and CTP, exists but it does not consider LHP. Makatsoris, Chang and Richards (2004) provide design architecture for the OPP in distributed enterprise environments. It first checks the ATP quantities along the entire supply chain nodes to satisfy customer orders. If not enough ATP exists, the system selects the manufacturing unit that is capable of satisfying these orders based on CTP and, subsequently, inserts them into the production plan. Christou and Ponis (2009) develop three deterministic models to improve coordination on both sides of the customer order decoupling point for MTS products without LHP. The second model decides the allocated ATP and the remaining CTP to produce the master plan to customer classes. If there is not enough ATP to promise an order proposal of a certain customer class, the third MILP model, can modify the MPS by using the remaining CTP also for this class. Brabazon and MacCarthy (2006) propose a simulation model to analyse and characterise the behaviour of Virtual-Build-ToOrder (VBTO) in the automotive industry, which takes advantages of MTS production. The search for the car to be promised to a customer begins by first selecting products from stock, then in the pipeline (similarly to the production plan) and lastly, if a suitable product has not been found, by initiating a BTO order. In view of the promising results, Brabazon and MacCarthy (2010) extend the above simulation model to an analytical one using a discretetime Markov process. 
Research into the OPP based on ATP and CTP but, in this case, for both MTS\&MTO products and without considering LHP, includes the following four papers: Robinson and Carlson (2007) propose an MILP model to decide whether or not to accept the order, and how to optimally allocate resources to it (ATP\&CTP check jointly). The requested quantity is pegged simultaneously against the aggregated uncommitted availability from five distinct sources that can be combined when promising an order: FGs Inventory, Final Assembly, Module Production (including module inventory), Production Scheduling and Remote Sourcing. The link between the OPP and the MPS is made in static way by means the forecast updating based on new orders accepted. Kalantari, Rabbani and Ebadian (2011) propose a decision support system (DSS) with several steps for batch order acceptance/rejection of MTO, MTS products and MTS/MTO product families. Customers are prioritised in the first step. Rough-cut capacity and rough-cut inventory are calculated in the second step by considering extra capacity, if required. If unavailability in capacity and materials occurs, some undesirable orders are rejected (only for the MTO and MTS/MTO products). MTS products are taken into account, but only in the second step to calculate the reserve capacity for their production. MTS products are not promised with MTO and MTS/MTO products. In the last step, accepted orders are considered in the shop floor's production schedule. Dumetz, Gaudreault, Thomas and Lehoux (2016) propose a simulation framework for divergent production systems with co-production. They define four order acceptance policies based on different availabilities: stock, ATP, CTP, and MIX (ATP to satisfy demand for MTS products, and CTP with demand for MTO products in an independent manner). Volling, Matzke, Grunewald and Spengler (2013) provide a review of the operation research models applied to planning capacities and orders in BTO automobile production, and show the co-existence of both BTS and BTO order fulfilment strategies. They indicate that if BTS production is used in parallel to BTO, the OPP comprises two sequential steps: 1) an ATP check when the customer request is searched against BTS cars and if no suitable match is found; 2) CTP is triggered and a new production order is inserted into the production plan.

Regarding the integration of MPS and OPP only for the BTO environments without LHP, Volling and Spengler (2011) explicitly propose a framework of order-driving planning that comprises two MILP models for both the OPP and MPS. Customer requests are checked only against current available production capacity (CTP) by the OPP. Then the MPS defines the factual production period of the previously accepted orders, based on quoted due dates and capacity constraints. One of the tested policies closely integrates both the MPS and OPP 
by anticipating some MPS aspects in the objective function of the OPP model, The added term is used to increase the stability of the MPS. Coordination mechanisms prove suitable to properly manage the trade-off between the different performance indicators in BTO automotive production.

From the analysed papers, the following gaps are detected (Table 1). Existing ATP and CTP calculation methods do not address any homogeneity requirement. The only two OPP models that deal with LHP exclusively consider MTS products and do not compute either CTP or CTP-LHP availabilities. Papers exist for both MTS and MTS\&MTO products that combine ATP and CTP, but do not consider the homogeneity required by customers. All these papers first compare ATP quantities with customers' requested ones: only when there is not enough ATP, CTP is computed (sequentially and/or independently for the MTS\&MTO products). One exception is the work by Robinson and Carlson (2007), in which the MILP model includes constraints for aggregate capacity availability (jointly). None of them, including the last one, takes into account LHP aspects, nor the detailed capacitated lot-sizing and loading problem with extra capacity, setups and minimum lot sizes considered in this paper to model the fact that different lots are not likely to be homogeneous. Although these works modify the MPS through the CTP consideration, if we exclude the work of Volling and Splenger (2011), the links between the MPS and the OPP are not explicitly described when considering dynamic OPP aspects.

Therefore, as a contribution, the MILP model and the methodology of this paper (Table 1) deal with the homogeneity requirements of customer orders for both MTS and MTO products by considering the homogeneous quantities in both uncommitted supply (ATP-LHP) and capacity (CTP-LHP). Unlike the reviewed works, an order line for MTS products can be partially promised with ATP, and also with scheduled additional lots based on CTP availabilities for MTS and MTO products jointly. In this paper, CTP-LHP uses the unpegged capacity that is not reserved for the master plan and, like three of the analysed papers, extends it through overtime whenever necessary. However, at the CTP availability level, new production lots can be added to the initial master plan before the MPS re-planning period elapses. Their possible excess, due to minimum lot sizes, can be used to serve future incoming orders. This allows a closer integration between both the OPP and MPS in a dynamic environment, as described in detail by the proposed methodology. In order to anticipate homogeneous quantities in new lots provided by each resource, CTP is modelled as a capacitated lot sizing and loading problem with setup times and costs for FG and families. 
Considering the CTP-LHP availability check jointly for MTS\&MTO products allows the better utilization of common resources than those methods based on allocation quotas of capacity per product type.

Therefore, as far as we are aware, there is no OPP model that combines ATP\&CTP and also considers the special features of LHP production systems (ATP\&CTP-LHP). Given the LHP of the FGs, new aspects of ATP, CTP and ATP consumption rules are taken into account in this work to satisfy the homogeneity customer requirements described in the next sections.

\section{Characteristics and assumptions of the OPP under study}

Before modelling the problem under study, the main blocks that characterise the OPP in hybrid MTS\&MTO environments with LHP are described below.

\subsection{Customer order proposals}

The order proposals considered during the OPP can be integrated by one or several order lines with different quantities requested for MTS and/or MTO FGs, but for the same due date specified by the customer. Due to LHP, customers require the FG units used to complete an order line to be of the same subtype (homogeneous), but they do not specify the subtype. As partial deliveries are not allowed, an order is assumed to be fulfilled if there is enough uncommitted availability for all its order lines for the due date, plus a possible maximum delay defined for each customer order.

\subsection{Manufacturing System}

The manufacturing system is assumed to comprise different production lines in parallel with limited capacity, and can be considered to belong to the same or to different production plants if transportation times are negligible. Production lines can manufacture a set of FGs according to an MTS and/or MTO strategy that are grouped into product families. Minimum lot sizes for FGs and families are defined to save setups. Item setups with cost and time consumptions among products of the same family exist (minor setups), but are smaller than between families (major setups). When scheduling CTP-LHP quantities, the production lines already prepared to produce a specific family or the same FG are considered to save setups. 


\subsection{Availability levels}

The ATP-LHP that derives from the on-hand inventory of an FG is expressed in terms of specific subtype $b\left(a t p O_{i b}\right)$ because they are known as it has been already produced and classified. However, as the subtypes for the planned lots in the MPS are not known, they need to be estimated. Since the batches of one same FG processed on different production lines and distinct time periods are not likely to be homogeneous, the ATP-LHP quantities for each FG are expressed in terms of time periods and production lines, like the MPS (Alemany, Boj, Mula \& Lario, 2010). For the same reason, the remaining normal and extra capacity that are not committed to produce the MPS are also calculated for each production line and time period (CTP-LHP). Therefore, in order to accomplish homogeneity requirements, it is not possible to accumulate the ATP-LHP quantities or new quantities that derive from the CTPLHP from different production lines and/or time periods to serve the same order line.

\subsection{OPP characteristics}

The solution to the OPP model provides the company with a decision about which customer orders are to be committed, and about the efficient allocation of the ATP-LHP and CTP-LHP quantities to these orders by accomplishing customer homogeneity requirements. The best solution depends on the pursued objectives which, for this case, maximises a weighted sum of two objectives. As usual, the OPP objective of maximising profits of committed orders is considered. However, as it is not possible to accumulate ATP-LHP quantities from different resources and time periods due to homogeneity requirements, the choice of reserving an ATPLHP from a specific homogeneous quantity of a subtype affects subsequent promises. The policy to guide ATP\&CTP-LHP allocation to orders in the proposed model is implemented by defining another objective to book the requested quantity from the most adjusted ATP quantity. The underlying assumption is that the bigger the ATP-LHP quantity, the stronger the probability of serving more customer orders with homogeneous quantities.

The proposed OPP model is valid for various execution modes (real-time and batch) by suitably defining the group of orders that must be promised in each iteration $s(O(s))$. In agreement with Meyr (2009), the following cases stand out:

- SOP-ATP-LHP: $O(s)$ comprises only one order in each iteration $s$.

- BOP-ATP-LHP: $O(s)$ comprises the orders whose arrival time falls in the batching interval of iteration $s$. 
- GOP-ATP-LHP: the model is executed only once. $O(s)$ comprises all the orders in the planning horizon $(\mathrm{T})$. It can be used as a benchmark to compare other execution modes.

Having solved the ATP\&CTP-LHP model, customers can be informed about the orders to be served and their real due dates. The model also provides the supply chain with information about the allocation of committed orders to ATP\&CTP-LHP quantities. If necessary, additional production lots to the initial MPS and extra capacity are also reported. Finally, the updated ATP-LHP and CTP-LHP quantities are calculated by the model as input for the next OPP execution in-between two consecutive MPS re-plannings.

\section{The ATP\&CTP-LHP model}

This section presents the notation used for the ATP\&CTP-LHP model and its formulation.

\subsection{Notation}

Tables 2 to 5 define the indices, sets, parameters and decision variables of the ATP\&CTPLHP model.

\begin{tabular}{|l|l|l|l|}
\hline$o$ & Customer order proposals waiting to be promised & $l$ & Production lines (productive resources) \\
\hline$i$ & $\begin{array}{l}\text { Finished goods (FGs) required in the considered } \\
\text { order proposals }\end{array}$ & $t$ & Time buckets \\
\hline$f$ & $\begin{array}{l}\text { Product families that belong to the previous FGs } \\
\text { required in the considered order proposals }\end{array}$ & $s$ & Iteration (model execution interval) \\
\hline$b$ & Existing subtypes of all the FGs & \multicolumn{2}{|l}{} \\
\hline
\end{tabular}

Table 2. Indices

\begin{tabular}{|l|l|l|l|}
\hline Os $(s)$ & $\begin{array}{l}\text { Set of customer order proposals to be } \\
\text { promised in iteration } s . \text { It contains those } \\
\text { customer order proposals whose arrival time } \\
t a_{o} \text { falls within the batching interval under } \\
\text { execution in iteration } s\end{array}$ & $F$ & $\begin{array}{l}\text { Set of all the product families that FGs } \\
\text { (i) belong to }\end{array}$ \\
\hline Osi $(i)$ & $\begin{array}{l}\text { Subset of customer order proposals from the } \\
\text { Os }(s) \text { that request some quantity of FG } i\end{array}$ & $I f(f)$ & $\begin{array}{l}\text { Set of FGs i requested in the customer } \\
\text { order proposals of iteration } s \text { that belongs } \\
\text { to family } f\end{array}$ \\
\hline$I$ & Set of all the FGs $i$ requested in the customer & $I l(l)$ & Set of FGs that can be processed by \\
\hline
\end{tabular}




\begin{tabular}{|l|l|l|l|}
\hline$I(o)$ & $\begin{array}{l}\text { Set of FGs } i \text { that are requested in customer } \\
\text { order proposal } o\end{array}$ & $F l(l)$ & $\begin{array}{l}\text { Set of product families that can be } \\
\text { processed by production line } l\end{array}$ \\
\hline$B(i)$ & Existing subtypes of FG $i$ that belong to $I$ & \multicolumn{2}{|l}{$l$} \\
\hline
\end{tabular}

Table 3. Sets

\begin{tabular}{|c|c|c|c|}
\hline$t a_{o}$ & Arrival date of customer order proposal $o$ & $t p_{i l}$ & $\begin{array}{l}\text { Time to process one unit of FG } i \text { on } \\
\text { production line } l\end{array}$ \\
\hline$d d_{o}$ & Due date of customer order pr & tsetupi $_{i l}$ & Setup time for FG $i$ on production line $l$ \\
\hline$q_{i o}$ & $\begin{array}{l}\text { Requested quantity of FG } i \text { in customer } \\
\text { order proposal } o\end{array}$ & tsetupf $_{f l}$ & $\begin{array}{l}\text { Setup time for family } f \text { on production } \\
\text { line } l\end{array}$ \\
\hline$n s_{o}$ & $\begin{array}{l}\text { Number of order lines (FGs) in customer } \\
\text { order proposal } o\end{array}$ & $\operatorname{lmini}_{i l}$ & $\begin{array}{l}\text { Minimum lot size of } \mathrm{FG} i \text { on } \\
\text { production line } l\end{array}$ \\
\hline$p_{o}$ & Profit of order $o$ & $\operatorname{lminf} f l$ & $\begin{array}{l}\text { Minimum lot size of family } f \text { on } \\
\text { production line } l\end{array}$ \\
\hline$h c_{i o}$ & $\begin{array}{l}\text { Inventory holding costs of } \\
\text { time period }\end{array}$ & $y i l_{i l t}$ & $\begin{array}{l}\text { Binary parameter with a value of } 1 \text { if } \\
\text { the production of FGI on production } \\
\text { line } l \text { during period } t \text { is planned in the } \\
\text { MPS, and } 0 \text { otherwise }\end{array}$ \\
\hline$b c_{o}$ & $\begin{array}{l}\text { Backlogging cost of customer order proposal } \\
o \text { per delayed time period }\end{array}$ & $y f l_{f l t}$ & $\begin{array}{l}\text { Binary parameter with a value of } 1 \text { if } \\
\text { the production of family } f \text { on } \\
\text { production line } l \text { during period } t \text { is } \\
\text { planned in the MPS, and } 0 \text { otherwise }\end{array}$ \\
\hline$r c_{o}$ & Cost of rejecting customer order proposal $o$ & $c p_{i l}$ & $\begin{array}{l}\text { Cost of producing an FG } i \text { unit on } \\
\text { production line } l\end{array}$ \\
\hline & $\begin{array}{l}\text { Maximum delay allowed for customer order } \\
\text { proposal } o \text { in relation to its due date } \\
\text { (expressed as an integer number of the time } \\
\text { period length). It is assumed that } \operatorname{rmax}_{o} \leq T \text { - } \\
d d_{o}\end{array}$ & csetupi $_{i l}$ & Setup costs of FG $i$ on production line $l$ \\
\hline$a t p O_{i b}$ & $\begin{array}{l}\text { Not yet assigned the existing stock of } \\
\text { subtype } b \text { of FG } i \text {, which becomes available } \\
\text { at the beginning of the planning horizon, and } \\
\text { can still be promised to customers during } \\
\text { iteration s }\end{array}$ & $\operatorname{csetupf} f$ & $\begin{array}{l}\text { Setup costs of product family } f \text { on } \\
\text { production line } l\end{array}$ \\
\hline$a t p_{i l t}$ & $\begin{array}{l}\text { Not yet assigned the supply of FG } i \\
\text { produced on manufacturing line } l \text {, which } \\
\text { becomes available during period } t \text {, and can } \\
\text { still be promised to customers during }\end{array}$ & che $_{l}$ & $\begin{array}{l}\text { Cost per unit of additional overtime } \\
\text { capacity consumed on production line } l\end{array}$ \\
\hline
\end{tabular}




\begin{tabular}{|c|c|c|c|}
\hline & iteration $s$ & & \\
\hline$c t p_{l t}$ & $\begin{array}{l}\text { Remaining available normal capacity of } \\
\text { production line } l \text { during period } t \text { that is not } \\
\text { reserved to manufacture the quantities } \\
\text { defined in the MPS }\end{array}$ & $\alpha_{P}$ & $\begin{array}{l}\text { Weight assigned to the maximising } \\
\text { profits objective }\end{array}$ \\
\hline ctphe $_{l t}$ & $\begin{array}{l}\text { Remaining available extra capacity of } \\
\text { production line } l \text { during period } t \text { that is not } \\
\text { reserved to manufacture the quantities } \\
\text { defined in the Master Plan }\end{array}$ & $\alpha_{A T P}$ & $\begin{array}{l}\text { The weight assigned to the objective of } \\
\text { accomplishing the ATP-LHP } \\
\text { consumption rule }\left(\alpha_{A T P}=1-\alpha_{P}\right)\end{array}$ \\
\hline
\end{tabular}

Table 4: Parameters

\begin{tabular}{|c|c|c|c|}
\hline$U S T_{o}$ & $\begin{array}{l}\text { Binary variable with a value of } 1 \text { if } \\
\text { customer order proposal } o \text { is served, } \\
\text { and } 0 \text { otherwise }\end{array}$ & $U A T P O_{i b}$ & $\begin{array}{l}\text { Updated } a t p O_{i b} \text { after committing the } \\
\text { customer order proposals of iteration } s \\
(O s(s))\end{array}$ \\
\hline$U S_{i o}$ & $\begin{array}{l}\text { Binary variable with a value of } 1 \text { if } \\
\text { FG } i \text { in customer order proposal } o \text { is } \\
\text { served, and } 0 \text { otherwise }\end{array}$ & & $\begin{array}{l}\text { Updated } a t p_{i l t} \text { after committing the customer } \\
\text { order proposals of iteration } s(O s(s))\end{array}$ \\
\hline$D D R_{o}$ & $\begin{array}{l}\text { Real delivery date } \\
\text { order proposal } o\end{array}$ & $M P I L_{i l t}$ & $\begin{array}{l}\text { Additional quantity to the MPS to be } \\
\text { produced of FG } i \text { on production line } 1 \text { during } \\
\text { period t. This quantity should respect the } \\
\text { minimum lot size of FG } i \text { and its } \\
\text { corresponding family }\end{array}$ \\
\hline$A D_{i o}$ & $\begin{array}{l}\text { Number of time periods before due } \\
\text { date } d d_{o} \text { assigned an ATP quantity } \\
\text { of FG I during period } t \text { to customer } \\
\text { order proposal } o\end{array}$ & $M P F L_{i l t}$ & $\begin{array}{l}\text { Additional quantity to the MPS to be } \\
\text { produced of family } f \text { on production line } l \\
\text { during period } t \text {. This quantity should respect } \\
\text { the minimum lot size of the family }\end{array}$ \\
\hline & $\begin{array}{l}\text { Number of time periods after due } \\
\text { date } d d_{o} \text { assigned an ATP of period } \\
\text { t quantity of FG } i \text { to customer order } \\
\text { proposal } o\end{array}$ & $C O N S_{l t}$ & $\begin{array}{l}\text { Capacity consumed by the additional } \\
\text { production lots to the MPS of all the FGs to } \\
\text { be produced on production line } l \text { during } \\
\text { period }\left(M P I L_{i l t}\right)\end{array}$ \\
\hline$R D T_{o}$ & $\begin{array}{l}\text { Number of time periods after due } \\
\text { date } d d_{o} \text { when customer order } \\
\text { proposal } o \text { is served }\end{array}$ & $H E_{l t}$ & $\begin{array}{l}\text { Extra capacity required to manufacture } \\
\text { additional production lots to the MPS on } \\
\text { production line } l\end{array}$ \\
\hline$D D F_{i o}$ & $\begin{array}{l}\text { Time period at which the requested } \\
\text { quantity } q_{i o} \text { of FG } i \text { of customer } \\
\text { order } o \text { is reserved. } \\
\text { This period is shorter or longer than } \\
\text { the due date of the order if there is }\end{array}$ & $U P I L_{i l t}$ & $\begin{array}{l}\text { Binary variable with a value of } 1 \text { if an } \\
\text { additional quantity to the MPS of FG } i \text { on } \\
\text { production line } l \text { or during period } \mathrm{t} \text { is } \\
\text { defined, and } 0 \text { otherwise }\end{array}$ \\
\hline
\end{tabular}




\begin{tabular}{|c|c|c|c|}
\hline & an advance or a delay, respectively. & & \\
\hline$Y A_{i o}$ & $\begin{array}{l}\text { Binary variable with a value of } 1 \text { if } \\
\text { the requested quantity of } \mathrm{FG} i \text { in } \\
\text { customer order proposal } o \text { involves } \\
\text { reserving an ATP quantity before } \\
\text { its due date (i.e., } \mathrm{AD}_{\mathrm{io}}>0 \text { ) }\end{array}$ & $U P F L_{f l t}$ & $\begin{array}{l}\text { Binary variable with a value of } 1 \text { if an } \\
\text { additional quantity to the MPS of family } f \\
\text { on production line } l \text { during period } \mathrm{t} \text { is } \\
\text { defined, and } 0 \text { otherwise }\end{array}$ \\
\hline$Y R_{i o}$ & $\begin{array}{l}\text { Binary variable with a value of } 1 \text { if } \\
\text { the requested quantity of FG } I \text { in } \\
\text { customer order proposal } o \text { involves } \\
\text { reserving an ATP quantity after its } \\
\text { due date (i.e., } \mathrm{RD}_{\mathrm{io}}>0 \text { ) }\end{array}$ & $S E T I L_{i l t}$ & $\begin{array}{l}\text { Binary variable with a value of } 1 \text { if a } \\
\text { setup takes place of FG } i \text { on production line } \\
l \text { during time period } \mathrm{t} \text {, and } 0 \text { otherwise }\end{array}$ \\
\hline$U O_{i o b}$ & $\begin{array}{l}\text { Binary variable with a value of } 1 \text { if } \\
\text { the requested quantity of } \mathrm{FG} i \text { in } \\
\text { customer order proposal } o\left(q_{i o}\right) \text { is } \\
\text { completely served by atp } O_{i b} \text {, and } 0 \\
\text { otherwise }\end{array}$ & $S E T F L_{f l t}$ & $\begin{array}{l}\text { Binary variable with a value of } 1 \text { if a } \\
\text { setup takes place of family } f \text { on production } \\
\text { line } l \text { during time period } t \text {, and } 0 \text { otherwise }\end{array}$ \\
\hline$U_{\text {iolt }}$ & $\begin{array}{l}\text { Binary variable with a value of } 1 \text { if } \\
\text { the requested quantity of } \mathrm{FG} i \text { in } \\
\text { customer order proposal } o\left(q_{i o}\right) \text { is } \\
\text { completely served by } a t p_{i l t} \text {, and } 0 \\
\text { otherwise }\end{array}$ & & \\
\hline
\end{tabular}

Table 5: Decision Variables

\subsection{Model Formulation}

The ATP\&CTP-LHP problem under study can be formulated with an MILP model (133 , which is described in next subsections.

$$
\operatorname{MAX}[Z]=\alpha_{P} * \frac{Z_{P}}{\sum_{o \in O s(s)} p_{o}}-\alpha_{A T P} \frac{Z_{A T P}}{T *\left(\sum_{i}|B(i)|+\sum_{i} \sum_{l}|I l(l)|\right)}=\alpha_{P} * \frac{Z_{P}}{\sum_{o \in O s(s)} p_{o}}-\left(1-\alpha_{P}\right) \frac{Z_{A T P}}{T *\left(\sum_{i}|B(i)|+\sum_{i} \sum_{l}|I l(l)|\right)}
$$

where: 


$$
\begin{aligned}
& Z_{P}=\sum_{o \in O S(s)} p_{o} * U S T_{o}-\sum_{o \in O S(s)} r c_{o} *\left(1-U S T_{o}\right)-\sum_{o \in O S(s)} b c_{o} * R D T_{o}-\sum_{o \in O S(s)} \sum_{i \in I(o)} h c_{i o}\left(D D R_{o}-D D F_{i o}\right) \\
& -\sum_{l \in} \sum_{i \in I l(l)} \sum_{t}\left(c p_{i l} * M P I L_{i l t}+\operatorname{csetupi}_{i l} * S E T I L_{i l t}\right)-\sum_{l} \sum_{f \in F l(l)} \sum_{t}\left(\operatorname{csetupf}_{f l} * S E T F L_{f l t}\right)-\sum_{l} \sum_{t} c h e_{l} * H E_{l t}
\end{aligned}
$$

$$
Z_{A T P}=\sum_{i} \sum_{b \in B(i)}\left(\frac{U A T P 0_{i b}}{a t p 0_{i b}+\varepsilon}\right)+\sum_{l} \sum_{i \in I L(l)} \sum_{t}\left(\frac{U A T P_{i l t}}{a t p_{i l t}+\varepsilon}\right)
$$

subject to:

$$
\begin{aligned}
& U A T P 0_{i b}=a t p 0_{i b}-\sum_{o \in O s i(i)} q_{i o} * U O_{i o b} \\
& \forall i \in I, b \in B(i) \\
& U A T P_{i l t}=a t p_{i l t}+M P I L_{i l t}-\sum_{o \in O s i(i)} q_{i o} * U_{i o l t} \\
& \sum_{b \in B(i)} U O_{i o b}+\sum_{l, t} U_{i o l t}=U S_{i o} \\
& \forall l, i \in I l(l), \quad t \\
& \forall o \in O s(s), \quad \forall i \in \mathrm{I}(o) \\
& \sum_{i \in I(o)} U S_{i o}=n s_{o} * U S T_{o} \\
& \forall o \in O s(s) \\
& A D_{i o}-R D_{i o}=d d_{o} * U S T_{o}-\sum_{l, t} U_{i o l t} * t \\
& \forall o \in O s(s), \quad \forall i \in I(o) \\
& A D_{i o} \leq d d_{o} * Y A_{i o} \\
& \forall o \in O s(s), \quad \forall i \in \mathrm{I}(o) \\
& Y A_{i o} \leq A D_{i o} \\
& R D_{i o} \leq \operatorname{rmax}_{o} * Y R_{i o} \\
& Y R_{i o} \leq R D_{\text {io }} \\
& Y A_{i o}+Y R_{i o} \leq 1 \\
& R D_{\text {io }} \leq R D T_{o} \\
& R D T_{o} \leq \sum_{i \in I(o)} R D_{i o} \\
& R D T_{o} \leq r \max _{o} * U S T_{o} \\
& D D R_{o}=d d_{o} * U S T_{o}+R D T_{o} \\
& D D F_{i o}=d d_{o} * U S T_{0}-A D_{i o}+R D_{i o} \\
& \sum_{i \in I l(l)}\left(t_{i l} * M P I L_{i l t}+\text { tsetupi }_{i l} * S E T I L_{i l t}\right)+\sum_{f \in F l(l)}\left(\text { tsetupf }_{f l} * S E T F L_{f l t}\right)=\operatorname{CONS}_{l t} \\
& \operatorname{CONS}_{l t} \leq c t p_{l t}+H E_{l t} \\
& H E_{l t} \leq c t p h e_{l t} \\
& \sum_{i \in I f(f)} M P I L_{i l t}=M P F L_{f l t} \\
& \forall o \in O s(s), \quad \forall i \in \mathrm{I}(o) \\
& \forall o \in O s(s), \quad \forall i \in I(o) \\
& \forall o \in O s(s), \forall i \in I(o) \\
& \forall o \in O s(s), \quad \forall i \in I(o) \\
& \forall o \in O s(s), \quad \forall i \in \mathrm{I}(o) \\
& \forall o \in O s(s) \text {, } \\
& \forall o \in O s(s) \\
& \forall o \in O s(s) \\
& \forall o \in O s(s), \forall i \in I(o) \\
& \forall l, t \\
& \forall l, t \\
& \forall l, t \\
& \forall l, f \in F l(l), \quad t
\end{aligned}
$$




$$
\begin{aligned}
& M P I L_{i l t} \leq M 1 * U P I L_{i l t} \\
& \text { UPIL }_{i l t} \leq \text { MPIL }_{i l t} \\
& M P F L_{f t t} \leq M 2 * U P F L_{f t} \\
& U P F L_{f t} \leq M P F L_{f f t} \\
& U P I L_{i l t}-y i l_{i l t} \leq S E T I L_{i l t} \\
& \text { SETIL }_{\text {llt }} \leq U P I L_{i l t} \\
& U P F L_{f l t}-y f l_{f t} \leq S E T F L_{f t} \\
& S_{E T F L} L_{f t} \leq U P F L_{f l t} \\
& l \min i_{i l} * \operatorname{SETIL}_{\text {llt }} \leq \text { MPIL }_{\text {ilt }} \\
& l \min f_{f l} * S E T F L_{f l t} \leq M P F L_{f l t} \\
& U S T_{o}, U S_{i o}, Y A_{i o}, Y R_{i o}, U 0_{i o b}, U_{i o l v}, U P I L_{i l t}, U P F L_{f l t}, S E T I L_{i l t}, S \text { TFF } L_{f l t} \text { BINARY } \\
& D D R_{o}, A D_{i o}, R D_{i o}, R D T_{o}, D D F_{i o}, U A T P O_{i b}, U A T P_{i l t}, M P I L_{i l t}, M P F L_{i l t}, I N T E G E R \\
& \mathrm{CONS}_{l,}, H E_{l t} \text { CONTINUOUS }
\end{aligned}
$$

\subsubsection{Objective Functions}

Two objective functions (2) and (3) are proposed, as is the possibility of combining them into a single objective (1) by a complete aggregation procedure, which consists in the weighted sum of the two objectives.

OF1: the first objective function (2) aims to maximise the profits made from the committed orders during iteration $s$, obtained as the difference between income through sales and costs incurred by rejecting an order (not serving), costs of serving an order with a delay (to defer), costs of advancing the reserve from some order lines (inventory) and costs due to CTP-LHP being included in the model. These are the costs incurred when manufacturing additional quantities of FGs to the MPS, such as production, setup (FG and family) and extra capacity costs.

As we can see, objective function $\mathrm{Z}_{\mathrm{P}}$ computes the holding costs for the ATP-LHP quantities allocated to orders before their real due date. However, holding costs are not incurred for unused ATP-LHP because these costs have been taken into account during the MPS when production lots have been balanced against the forecast demand that includes accepted orders. Due to the minimisation of production and setups costs $\left(c p_{i l}\right.$ and $\left.c s e t u p i_{i l}\right)$ in 
OF1, new production quantities $\left(M P I L_{i l t}\right)$ should be defined to not exceed those strictly needed to complete the order. In this case, the new quantities are integrated into the ATP-LHP reservation and holding costs are computed (see Eq. (5)). Only when new scheduled production lots are bigger than the required quantities to complete customer orders, because the minimum lot size should be respected, can additional holding costs appear apart from those intrinsic for the OPP. At this point, it is impossible to compute them in the OPP model because these costs depend on subsequent customer order proposals and, therefore, on updated forecasts. These new forecasts, along with other inputs, are taken into account during the next MPS execution. As a result, previously defined lots can be changed according to the new input data and objectives followed by the MPS, such as minimisation of inventory holding costs.

OF2: Through the second novel objective function (3), the ATP-LHP consumption and assignation rules to committed orders are implemented to maximise the possibility of promising future incoming orders. As previously mentioned, several homogeneous ATP-LHP quantities may exist from which the amount to meet the order proposals of a specific iteration $s$ can be reserved. If maximising profits is the only objective, the obtained solution can be any of the feasible alternatives; that is, it is randomly chosen and does not, therefore, implement any policy. Nevertheless, due to LHP it is impossible to accumulate ATPs from different production lines and distinct time periods for the same FG. Therefore, the choice of reserving ATP from a specific homogeneous sublot affects subsequent promises.

As an illustrative example, let's assume for specific time period $t$ for a given FG $i$ that there are two homogeneous ATPs: one with a value of atp1 $=800$ units and the other with a value of atp $2=320$ units. Let's also assume that three orders $(o 1, o 2, o 3)$ arrive one after another with due dates $d d_{o 1}=d d_{o 2}=d d_{o 3}=t$. Finally, let's assume that the first includes a requested quantity of 250 units $\left(q_{o 1}\right)$, the second has a requested quantity of 600 units $\left(q_{o 2}\right)$ and the third a requested quantity of 70 units $\left(q_{o 3}\right)$, and that a real-time response must be given to all three. Figure 1 provides four possible alternatives (solutions A to D) to assign ATP-LHP to the incoming orders. 

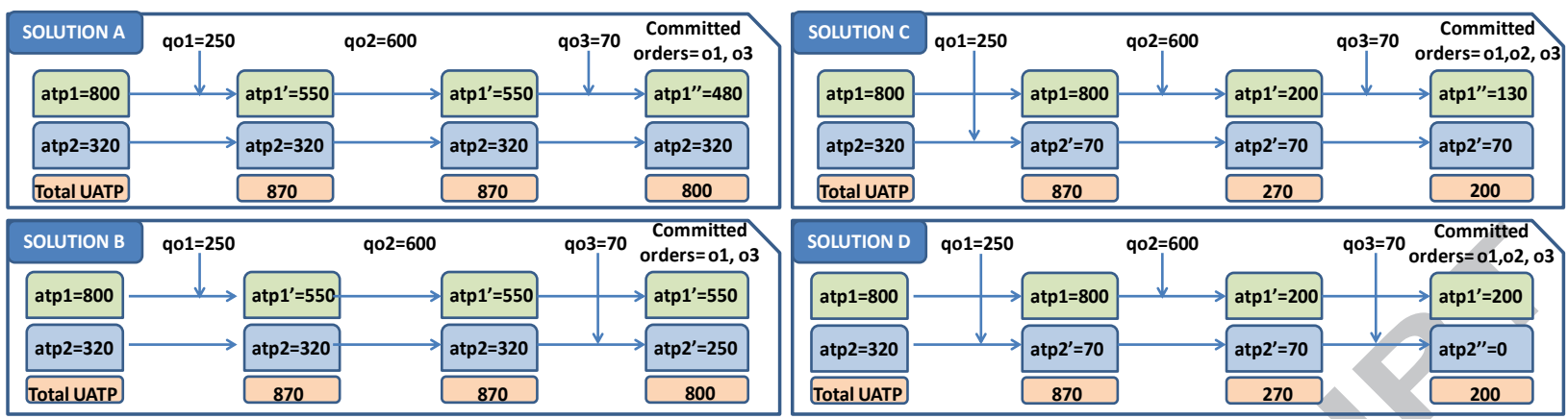

Figure 1. Possible solutions to commit orders.

When promising the first order, it is possible to reserve the ATP-LHP of both homogeneous quantities atp1 and atp2. Solutions A and B assign 250 units of atp1, while solutions C and D assign 250 units of atp 2 for the first order, where the updated atp $\left(\right.$ UATP) equals atp $1{ }^{\prime}=550$ and atp2' $=70$, respectively. Solutions A and B cannot commit the second order, whereas solutions $\mathrm{C}$ and D assign ATP from atp1 with the updated atp1' $=200$. Finally, the third order can be committed by all the solutions. From the above examples, we deduce that when several alternatives are available to assign homogeneous ATPs of the different subtypes to an order, the policy made to select one of these alternatives affects future commitments and, therefore, system performance.

In this work, the ATP-LHP assignation rule consists in reserving ATP-LHP for orders from which the ATP homogeneous quantity best adjusts to those required $\left(q_{i o}\right)$ in an attempt to exhaust as many ATP homogeneous quantities as possible. This is based on the notion that the likelihood of serving any order with homogeneous quantities from a few ATP-LHPs with a large homogeneous quantity is much greater than from many ATP-LHPs with a small homogeneous quantity. This policy would be that implemented in solution D.

Now we move on to formulate this policy mathematically. It is reasonable to believe that this is the equivalent of minimising the total remaining uncommitted amount (UATP) after having promised incoming orders. As seen from solutions A to D, this objective commits as many orders as possible (solutions C and D). However, when the same customer orders are committed, the sum of all the updated ATPs (UATP) is the same for all the possible alternatives. As shown for the third order in solutions C and D, it is promised by atp1' and atp2', respectively, and gives the same total updated ATP (UATP=200). Thus our consumption rule should reserve the ATP from atp2' $=70$ because it best adjusts to $q_{o 3}=70$ and it exhausts this ATP-LHP. 
In order to implement this consumption rule, the minimisation of the sum of ratios between the updated ATP (UATP) and the initial ATP (atp) in each assignment (3) is proposed $\left(\mathrm{Z}_{\mathrm{ATP}}\right)$ for both the ATP-LHP in stock (first term) and the planned ATP-LHP (second term). If no additional production quantity is defined for each ATP-LHP, this ratio always equals or is lower than 1 . In another case, the UATP can be greater than the initial atp (i.e., if minimum lot sizes have been manufactured), and the ratio is higher than the unit. As this fact increases the $\mathrm{Z}_{\mathrm{ATP}}$ value, it goes against the minimisation objective. Therefore, the policy of not scheduling additional production quantities for committing an order, unless absolutely necessary, is also achieved by this second objective. Since initial ATPs $\left(a t p 0_{i b}\right)$ can be zero in each iteration $s$, a very small quantity $(\varepsilon)$ is added to the denominator to prevent a division by zero.

Table 6 reports the allocation of orders to the ATP-LHP quantities obtained by applying the OF2 to the promising of the three above-mentioned customer orders, which should be promised online by respecting the First-Come-First-Served policy. When the first order $o 1$ arrives, the initial atps (atp1=800 and atp2=320) are available. If we choose to serve $o 1$ from atp 1 (first row), the updated UATP1 should equal 550 (800-250) and UATP2 should remain the same. If we choose to serve $o 1$ from atp2 (second row), the updated UATP2 should equal 70 (320-250) and UATP1 should remain the same. Having calculated the updated ATPs (UATP1 and UATP2) for each possibility, the ratios of Eq. 2 can be derived. As seen, both possibilities allow us to commit order $o 1$, but the second assignation provides us with a lower $\mathrm{Z}_{\text {ATP }}$ value $(1,21$ ys. 1,68). Consequently, this second option is chosen (coloured row). Then for second order 02 , the initial atp1 and atp2 coincide with UATP1 and UAPT2 for the first assignment. This procedure is repeated for this second order $o 2$ and for the third one, o3. For the second order $o 2$, only one row appears because it is only possible to serve it by reserving its corresponding quantity from atp1. As seen, the implementation of the assignation rule through OF2 leads to the previously desired solution D, with all three orders to be committed (Table 6).

\begin{tabular}{|l|l|l|l|l|l|l|l|l|l|}
\hline \multirow{2}{*}{ Order } & \multirow{2}{*}{$\mathbf{q}_{\mathbf{o}}$} & atp1 & \multirow{2}{*}{ atp2 } & $\begin{array}{l}\text { Assign } \\
\text { ATP from }\end{array}$ & UATP1 & UATP2 & UATP1/atp1 & UATP2/atp2 & $\mathbf{Z}_{\text {ATP }}$ \\
\hline \multirow{2}{*}{$o 1$} & \multirow{2}{*}{250} & \multirow{2}{*}{800} & \multirow{2}{*}{320} & atp1 & 550 & 320 & $550 / 800=0,68$ & $320 / 320=1,00$ & 1,68 \\
\cline { 5 - 10 } & & & atp2 & 800 & 70 & $800 / 800=1,00$ & $70 / 320=0,21$ & 1,21 \\
\hline$o 2$ & 600 & 800 & 70 & atp1 & 200 & 70 & $200 / 800=0,25$ & $70 / 70=1,00$ & 1,25 \\
\hline \multirow{2}{*}{$o 3$} & \multirow{2}{*}{70} & \multirow{2}{*}{200} & \multirow{2}{*}{70} & atp1 & 130 & 70 & $130 / 200=0,65$ & $70 / 70=1,00$ & 1,65 \\
\cline { 5 - 9 } & & & atp2 & 200 & 0 & $200 / 200=1,00$ & $0 / 70=0,00$ & 1,00 \\
\hline
\end{tabular}

Table 6. Implementation of the ATP-LHP consumption rule that leads to solution D. 


\subsubsection{Global objective function}

The global objective function (1) consists in a combination of the two previous objectives by the sum-weighted method (Marler \& Arora, 2010). In order to combine them, it is necessary to scale both functions so they fall between 0 and 1 . The denominators of the first and the second term of the global objective function $(Z)$ represent an upper bound of the value, which can be achieved by $\mathrm{Z}_{\mathrm{P}}$ and $\mathrm{Z}_{\mathrm{ATP}}$ during each iteration $s$, respectively. The decision maker must also assign a weight ( $\alpha_{\mathrm{P}}$ and $\alpha_{\mathrm{ATP}}$ ) to the different objectives so that the sum of both weights becomes the unit $\left(\alpha_{\mathrm{P}}+\alpha_{\mathrm{ATP}}=1\right)$. The closer a weight comes to 1 , the greater the importance to achieve this objective for the decision maker.

Obviously, the OPP optimal solution depends on the weights assigned to each objective and the upper bounds in the denominators of Equation (1). For the first aspect, the experimental design of Section 6 intends to gain some insight into the effect on the solution of the objective weights in a dynamic environment. The same methodology can be replicated by the decision maker to select appropriate weights. For the second aspect, it is necessary to stress that the proposed upper bounds represent the maximum possible values of each objective to ensure that each objective function term belongs to the $[0,1]$ interval with the specified input data. Along these lines, the maximum $Z_{P}$ value is achieved in an ideal, but possible situation, in which all the customer orders in a specific iteration $s$ are committed with no costs. No costs are possible if all the orders are reserved from the existing ATP-LHP during a time period that equals their due date and if no CTP-LHP quantities are necessary. The maximum $\mathrm{Z}_{\mathrm{ATP}}$ value is achieved if all the ATP-LHP quantities remain the same after execution $s$, which is the equivalent to the possible situation of not committing any order.

\subsubsection{Constraints}

Constraints (4 to 6) ensure that quantities are reserved from homogeneous ATP-LHP quantities to commit orders. Constraint (4) calculates the remaining ATP-LHP in stock for each subtype and FG $\left(\operatorname{UATP}_{i b}\right)$ by means of the difference of the initial ATP-LHP $\left(a t p 0_{i b}\right)$ and those committed customer order lines reserved from it. As $U A T P 0_{i b}$ is defined as non-negative, the total quantity committed and assigned to this initial ATP-LHP can never exceed the initially available one. Constraint (5) is used to calculate the remaining planned ATP-LHP for 
each FG $i$, line $l$ and time period $t$ based on the initial ATP-LHP $\left(a t p_{i l t}\right)$ and the new scheduled production quantities $\left(M P I L_{i l t}\right)$, minus the quantities committed to serve the orders in iteration $s\left(\sum_{o \in O s i(i)} q_{i o} * U_{i o l t}\right)$. It is assumed that the previous existing ATP-LHP $\left(a t p_{i l t}\right)$ and the new production quantities $\left(M P I L_{i l t}\right)$ are homogeneous (belong to the same subtype) because they are manufactured on the same production line and during the same time period. As seen in Constraints (4) and (5), the total quantity requested in an order line $\left(q_{i o}\right)$ should be completely reserved from the same ATP-LHP quantity subtype to, thus, ensure the homogeneity of the units in the order. It is worth stressing that if $t \geq 1$, the subtype to which FG $i$ belongs is unknown because its production is still to be completed, and it remains to be classified. This is the reason why subtype $b$, to which FG $i$ belongs, is distinguished only for the ATP-LHP in $\mathrm{t}=0\left(\operatorname{atp} 0_{i b}\right)$ in Constraint (4). For $\mathrm{t} \geq 1$, the batches of one same FG produced on different lines and during distinct time periods are considered, which leads to heterogeneous subtypes, as in Constraint (5).

Through Constraint (6), a decision is made if the order line of FG $i$, which belongs to order $o$, is served $\left(U S_{i o}=1\right)$ or not $\left(U S_{i o}=0\right)$. If it is served, the allocated quantity can only be reserved from a single subtype (real or planned); i.e., only one binary variable $\left(U O_{i o b}\right.$ or $\left.U_{\text {iolt }}\right)$ should equal 1. If not served, no allocation is made.

Constraint (7) forces to serve the order $o\left(U S T_{o}=1\right)$ when all its order lines $i$ are served ( $\left.U S_{i o}=1\right)$. Otherwise, the order cannot be completely served if only one of them is not served; that is, it is rejected ( $U S T_{o}=0$ and $U S_{i o}=0$ for all $\mathrm{i}$ ). Constraint (7) acts also in the opposite way; that is, if the order is not served $\left(U S T_{o}=0\right)$, it is senseless to serve any of its order lines separately ( $U S_{i o}=0$ for all i) because no partial deliveries are allowed.

As some delay can be accepted by customers, the real committed due date is calculated for each order through Constraints (8) to (18). It coincides with the original order due date if no delay exists. Constraint (8) calculates the delay $\left(R D_{i o}\right)$ or advance $\left(A D_{i o}\right)$ of each order line of FG $i$ in relation to the due date of order $o\left(d d_{o}\right)$, and also depending on whether this order is served or not. If this order is not served, then none of its lines is served given Constraint (7). Consequently, neither delays nor advances are calculated. In the objective function, the 
penalty only appears for not serving the order. When an order line of FG $i$ in order $o$ is served from $\operatorname{atp} 0$, that is $\mathrm{t}=0$, then the advance is $d d_{o}$.

On the one hand, Constraint (9) indicates that the advance of an order cannot be longer than the due date, which forces the associated binary variable to take a value of 1 when an advance occurs. On the other hand, Constraint (10) forces binary variable $Y A_{i o}$ to be zero when there is no advance.

Constraint (11) indicates that the maximum delay cannot be longer than the maximum one permitted for this order $\left(\operatorname{rmax}_{o}\right)$. If a delay occurs for an order, associated binary variable $Y R_{i o}$ takes a value of 1 , and Constraint (12) forces this variable $Y R_{i o}$ to take a value of 0 if there is no delay. Constraint (13) is employed to ensure that there is a delay or an advance, or neither, to deliver an FG $i$ in a specific order, but not both at the same time. Constraint (14) implies that the delay in order $o$ equals the maximum delay of the order lines that comprise it because the order cannot be served until all the order lines are reserved. Constraint (15) ensures the impossibility of delaying an order or if any of its order lines are delayed. Constraint (16) forces a situation in which a delay in an order cannot exceed the maximum delay established for this order (should this order be served). If the permitted maximum delay equals zero for all the orders, it is a specific case in which serving with delays is not allowed. Through Constraint (17), the real date $\left(D D R_{o}\right)$ on which order $o$ is to be delivered is calculated, which is the due date, plus the delay in order o. It is necessary to stress that the real due date coincides with the customer due date if no delay exists, and independently of the time period from which the order lines were previously reserved. If an advance exists, they will remain in the inventory until delivered. With Constraint (18), the real reservation date of order line $i$ of customer order proposal $o$ is defined. The difference between the real order date $\left(D D R_{o}\right)$ and the reservation date $\left(D D R_{o}-D D F_{i o}\right)$ provides the number of time periods that the quantity of the order line $\left(q_{i o}\right)$ is stored. This allows a precise calculation of holding costs.

The remaining constraints (19 to 32) implement the CTP-LHP part of the OPP model. Constraint (19) computes the capacity consumption on production line $l$ during period $t$ due to the additional FGs production quantities to the MPS and also to the FG and family setup times if this last one is necessary. Constraint (20) ensures that the above capacity consumption is no higher than the uncommitted normal capacity $\left(c t p_{l t}\right)$ and the extra capacity required $\left(H E_{l t}\right)$. Constraint (21) does not allow any required extra capacity $\left(H E L_{l t}\right)$ for manufacturing new lots to exceed the remaining extra capacity $\left(c t p h e_{l t}\right)$. 
Constraints (22 to 30) are defined to compute FGs and family setups. Constraint (22) computes the additional quantity to be produced for a family by summing the additional production quantities of the FGs that belong to the family. Through Constraints (23) and (24), the relationship between the produced quantity of FG $i$ (MPILilt $)$ and the binary variable (UPILilt) indicates that an additional quantity is defined, if necessary. If the former is above 0 MPIL $\left._{i l t}>0\right)$, the latter takes a value of 1 (UPIL $\left.L_{i l t}=1\right)$ through Constraint (23). If no further production is necessary $\left(M P I L_{i l t}=0\right)$, the binary variable $\left(U P I L_{i l t}=0\right)$ takes a value of 0 due to Constraint (24). Constraints (25) and (26) are analogous to Constraints (23) and (24), but are defined for product families. M1 and M2 are very big numbers. Constraint (27) establishes that a setup of FG $i$ on production line $l$ during period $t$ is necessary $\left(\right.$ SETIL $_{i l t}=1$ ) if an additional production quantity is scheduled on this production line $l\left(U P I L_{i l t}=1\right)$, and if this same production line has not been previously prepared to produce this FG $i\left(y i l_{i l t}=0\right)$. A new setup never occurs if no further production quantity is defined (28). Constraints (29) and (30) are analogous to Constraints (27) and (28), but for families instead of FGs. Constraint (31) ensures that if a new setup occurs, the additional FG production quantity must be larger than or equal its minimum lot size. If a new setup does not take place, additional quantities are added to previous ones, which already met the minimum lot size. Constraint (32) is similar to Constraint (31), but is formulated for product families. Finally, Constraint (33) shows the definition of the variables.

It is important to note that the model allows orders with FGs produced according to the MTS and/or MTO strategy to be promised. For the former, ATP-LHP exists in advance. It is also possible to enlarge lots or schedule additional ones using CTP-LHP. For the latter, ATPLHP does not exist or is not considered, and orders are promised based only on CTP-LHP.

\section{Integration Methodology of the Order Promising and the Master Production Schedule}

The proposed OPP model can modify the initial MPS, if necessary, by either enlarging existing lots or scheduling new ones based on CTP-LHP quantities. In this section, the contributions regarding the dynamics of the OPP and its integration with the MPS in a cyclic approach are detailed according to the methodology shown in Figure 2. 
The process begins by executing the MPS, which can be classified as a capacitated lot sizing and loading problem (CLSLP), where lots are programmed to ensure that demand forecasts for MTS-Products (1) and already committed orders by the OPP for MTS\&MTO products (2) are covered by the capacity of common productive resources (3). The MPS is executed (4) based on a rolling horizon scheme that covers T planning periods. Every time the MPS is executed, the new planned lots (5), the required (booked) capacity (6a) for producing them and the setup status for FGs and families (6b) are passed to the ATP-LHP and the CTPLHP modules. These two last modules calculate their uncommitted availability levels taking into account the previous accepted orders (2), and the initial availability of production resources, (3), respectively. It is assumed the CTP-LHP availability is zero for the frozen horizon of the MPS. This implies that the OPP will be able to commit orders with the due dates inside a frozen horizon based only on existing ATP-LHP.

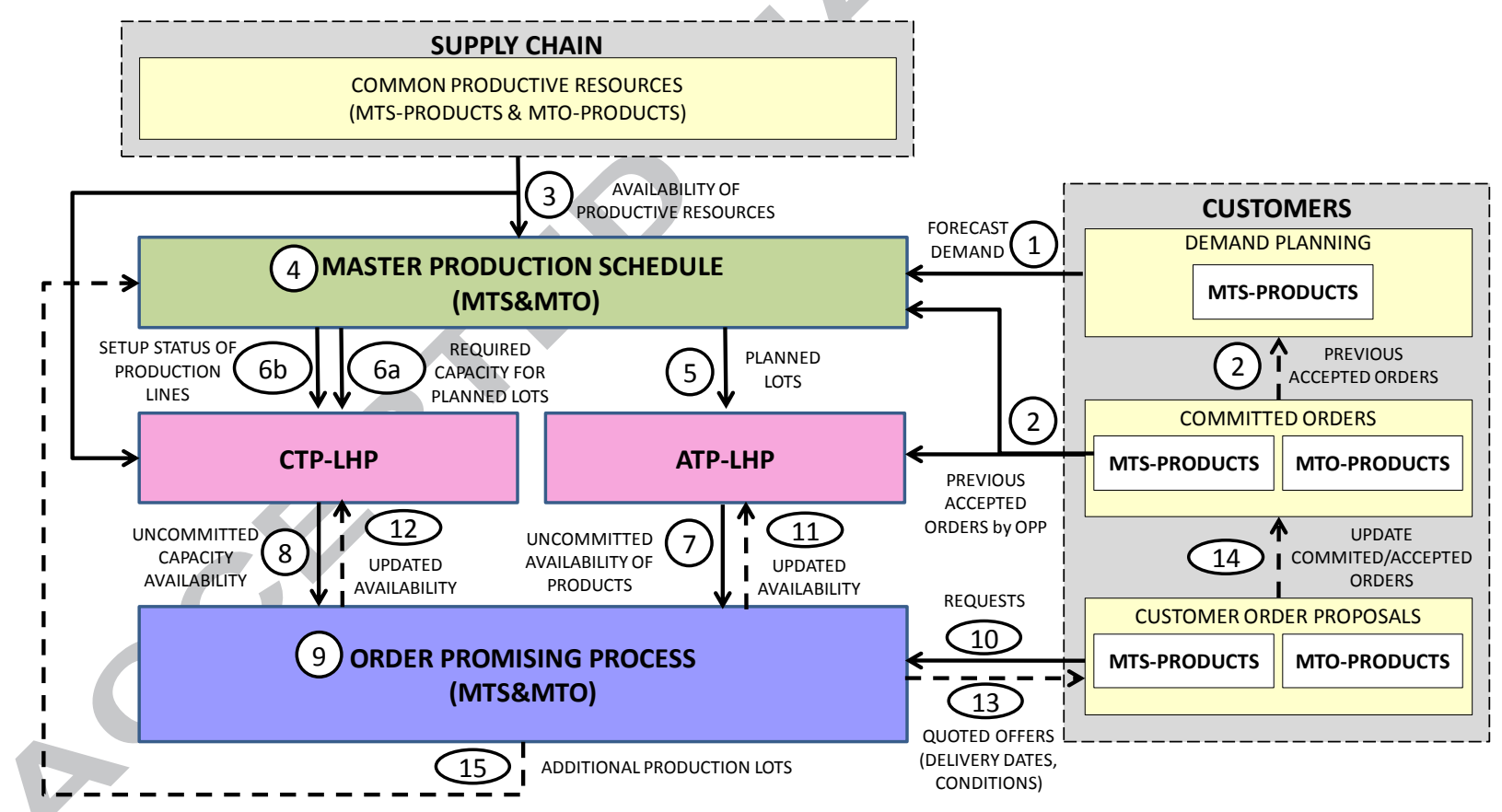

Figure 2. Methodology to integrate both the OPP and MPS

The ATP-LHP (7) and CTP-LHP (8) quantities are used as input to the OPP (9), whose horizon should be equal or lower than the MPS horizon. The planning period of the MPS should be an integer multiple of the OPP time period, and it is necessary to disaggregate MPS quantities if the OPP time period is shorter than the MPS one. For our case, it is assumed that the durations of both the MPS and OPP planning periods are equal. 
Based on uncommitted availabilities (7) and (8), the OPP (9) is executed either every time a customer order proposal arrives (10) for on line execution mode, or once the batching interval has elapsed. For both cases, all the customer order proposals (requests) with an arrival time that falls within the batching interval are taken into account (10). Customer order proposals can include both MTS-Products and MTO-Products. Based on ATP-LHP and CTPLHP quantities, the OPP simultaneously determines: a) the assignation of ATP-LHP quantities or new quantities to be scheduled for MTS-Products order proposals; b) new production lots for accomplishing customer order proposals for MTO-Products; c) the updated ATP-LHP (11) and CTP-LHP (12) quantities after executing the OPP; d) the possibility of serving or not (13) the order on the due date with the required quantity. The resulting accepted orders update the global committed orders (14).

The OPP is usually executed several times between two consecutive MPS replannings. For these OPP iterations $(s)$, it is necessary to update the ATP-LHP quantities by bearing in mind the committed orders and, if necessary, additional production quantities. Since new production quantities can be defined, updating the uncommitted resource availability (CTP-LHP) and the setup status of the production lines for FGs and families must be carried out. Equations (34) to (39) show how some of the OPP parameters updated from iteration $(s)$ to $(s+1)$ are achieved:

$$
\begin{aligned}
& \operatorname{atp} 0_{i b}(s+1)=U A T P 0_{i b}(s) \\
& \forall i \in I, b \in B(i) \\
& \operatorname{atp}_{\text {ilt }}(s+1)=\operatorname{UATP}_{\text {ilt }}(s) \\
& \forall i \in I, l, t \\
& c t p_{l t}(s+1)=\operatorname{Max}\left[0, c t p_{l t}(s)-\operatorname{CONS}_{l t}(s)\right] \quad \forall l, t \\
& \text { ctphe }_{l t}(s+1)=\text { ctphe }_{l t}(s)-H E_{l t}(s) \quad \forall, t \\
& y i l_{i l t}(s+1)=y i l_{i l t}(s)+\operatorname{SETIL~}_{i l t}(s) \quad \forall l, i \in I l(l), t \\
& y f l_{f l t}(s+1)=y f l_{f l t}(s)+\operatorname{SETFL}_{f l t}(s) \quad \forall l, f \in F L(l), t
\end{aligned}
$$

Finally, every time the MPS re-planning period elapses, forecasts (1), committed orders (2) and productive resources availability (3) are updated and the MPS (4) is triggered again. The updated production lots in the MPS of this new planning cycle can differ from those that derive from the OPP because updated forecasts can differ from initial ones. Based on them, new ATP-LHP quantities and new capacity requirements, which are translated into new CTP-LHP quantities, are passed on to the OPP, which is once again executed, and so on. 
The OPP model takes into account the lots already scheduled in the MPS and the costs incurred when either scheduling new lots or enlarging existing ones based on CTP-LHP. This anticipates MPS behaviour and attempts to confer it more stability. If the customer order proposals for the MTS products jointly with accepted ones during each period do not exceed the forecasts for this period, there will be enough ATP and no stock out situations will occur with the previously defined MPS lots. If customer order arrivals of the MTS products exceed forecasts and not enough ATP-LHP exists, the OPP model will decide if the MPS modification is possible and profitable. Finally, the orders for the MTO products necessarily require additional scheduled quantities. For both cases, the OPP model through the ATP-LHP and CTP-LHP considerations ensures feasible and reliable commitments with customers.

\section{Application to a ceramic company}

The ATP\&CTP-LHP model was tested with different sets of realistic data from a large Spanish ceramic tile firm. Ceramic production plants have several production lines (processors in parallel) of limited capacity that can process different FGs. Once produced, FGs are classified into subtypes based on three attributes: qualities (aspect), tone (colour degree) and gage (thickness). The consideration of three qualities, two tones and three gages usually implies that one same model (the FG) can lead to 13 different references (subtypes). This situation increases the volume of information and makes system management more complex.

The usual OPP involves customers requesting quantities of different first quality products in one same order (i.e., ceramic wall and floor, baseboard). Customers also require the units of one same product in the order to be homogeneous (same tone and gage) for functional and aesthetic reasons because they are normally placed and presented together. The Spanish ceramic company under study has its own nationwide network of points of sale. The company can promise orders of different customer types such as: the selling points that belong to, or not, the company that serves small customers, large and small constructions, national distributors and export clients. Each client type presents very different characteristics as regards the requesting volume, lead times and customisation levels of FGs, which has led the 
company to produce MTS if demand is high and regular, and to produce MTO if demand is sporadic and irregular.

One of the main problems of ceramic companies is the high volumes of stock spread throughout their network nodes that can become obsolete, even without achieving a high customer service level. This is because of the LHP consequences and the order promising practices carried out. The commercial (sales) staff is in charge of promising customer orders based on their own criteria and the ATP information provided by a computer system. As the salespersons' main objective is to maximise customer satisfaction, for MTS products they tend to usually book ATP from the earliest possible period to ensure that a customer is served on time, and from the biggest ATP quantity to avoid future homogeneity problems. If not enough ATP exists for small size MTS orders, they provide a due date based on a fixed lead time. If not enough ATP quantity exists for big sized orders of MTS or MTO products, a nonautomatic procedure is executed to commit these orders by modifying the MPS based on CTP.

The above procedure is followed for each customer order line, which entails high time investments. If not all the customer orders can be served, a complex and very time consuming reallocation process of availabilities begins during which even to find a feasible solution is not ensured. If certain customer orders are not served on time, a renegotiation process with customers begins in order to define a new due date. This negatively impacts the customer service level and the company's efficiency.

On the other hand, reserving from the earliest ATP despite the order due date endangers the commitment of orders arriving at the company later, but with an earlier due date, unless an ATP reallocation was made or additional lots in the MPS were scheduled. Besides, reserving from the largest homogeneous ATP regardless of order size could endanger serving large orders with homogeneous amounts if at least new production lots were scheduled. Finally, dealing independently with MTO and MTS products hinders the company from efficiently using available resources. The proposed model attempts to overcome these drawbacks by providing salespersons with an optimal solution to invest less time and fewer efforts. 


\subsection{Experimental design}

The numerical study presented herein focuses on validating the proposed model and on analysing the impact of ATP-LHP consumption rules on different performance measures in three supply scenarios and in distinct execution modes, both with and without CTP-LHP. The obtained results can be used to gain insights into prescribing how the ceramic firm under study should adjust its ATP-LHP consumption rules. This subsection describes the characteristics of the data employed for all the generated problem types. Bearing in mind that the purpose of this section is to validate the OPP model and to characterise its behaviour, some simplifications on real data have been made to obtain optimal solutions. This experimental procedure prevents the results from being influenced by the complexity of the model, which can lead to not entirely correct conclusions because the optimal solution is not reached. In order to provide the reader a rough idea about the magnitude of these simplifications, they are reported in this section.

Model data are based not only on historical SC information (demand data), but also on the mean real values provided by this SC (prices and costs). While the physical configuration was slightly modified for confidentiality reasons, it respects the structure described in this article, but approximately halves it. The data that are common to the different generated problem types are: two plants, one with two production lines and the other with one production line. They are capable of processing four FGs in accordance with a mixed MTS/MTO strategy.

The model horizon (T) comprises 8 weeks (approximately 2 months) and coincides with the company's real OPP period and horizon length. Although up to 13 different subtypes can exist for each FG, it is usual that an average of three subtypes appears per FG for the considered planning horizon length. For this reason, three subtypes are considered per FG in the simulation tests. The four contemplated FGs are assumed to belong to two families and, as such, FG1 and FG2 belong to Family 1, and FG3 and FG4 to Family 2.

The company currently receives between 300 and 400 order proposals per week, where approximately $80 \%$ of orders comprise between 1 and 4 order lines. For the experiments carried out in this paper, the arrival of 100 orders proposals that contain from one to four lines per order with the same probability (uniform distribution) as that among four different FGs is simulated. The same 100 order proposals were considered to be the input of all the problem types. Table 7 contains the sale prices per $\mathrm{m}^{2}\left(p i_{i}\right)$, the backlog costs per $\mathrm{m}^{2}\left(b c i_{i}\right)$ and the inventory holding costs per $\mathrm{m}^{2}$ of FG i and period $\left(h u c_{i}\right)$ provided by the company. Rejection 
costs are estimated by the company to be $15 \%$ of sale prices. Parameters $p_{o}, b c_{o}, h c i_{o}$ and $r c_{o}$ for each order of the ATP\&CTP-LHP model were calculated by multiplying quantity $q_{i o}$ by the corresponding unitary parameters $p i_{i}, b c i_{i}, h u c i_{i}$ and $r c i_{i}$, and then summing up all the FGs $I$ included in the customer order proposal.

To define the order quantities for each FG, three classes of orders were defined based on a fixed size for each class (Table 8). Each class can be assimilated with final customers, independent distributors and construction firms. A probability of occurrence of $1 / 3$ was assigned to each class. Then the cumulative probabilities and their respective intervals were derived. To estimate the quantity requested per FG on each order line, a random number was generated, based on the interval it belonged to, and a specific order quantity was assigned (Monte-Carlo method). The arrival time of each order $\left(t a_{o}\right)$ was generated by adding to the last order arrival time and the additional time generated randomly inside the uniform distribution within the interval [0,0.06], as follows: $t a_{o}=t a_{o-1}+\operatorname{random}[0,0.06]$ periods, whereas its associated due date $\left(d d_{o}\right)$ was generated randomly from among $\left[t a_{o}, T\right]$. The maximum delay $\left(\operatorname{rmax}_{o}\right)$ was established during two periods for all the orders. Table 9 provides the CTP-LHP extra and normal uncommitted availability, as well as FG production and setup costs and times.

\begin{tabular}{|l|l|l|l|l|}
\hline Parameters/ & $\boldsymbol{p} \boldsymbol{i}_{\boldsymbol{i}}$ & $\mathbf{b c i _ { i }}$ & huci $_{\boldsymbol{i}}$ & $\boldsymbol{r c i}_{\boldsymbol{i}}$ \\
\hline Finished Goods & 18 & 0.90 & 0.072 & 2.7 \\
\hline FG2 & 16 & 0.85 & 0.065 & 2.4 \\
\hline FG3 & 12 & 0.70 & 0.060 & 1.8 \\
\hline FG4 & 10 & 0.50 & 0.055 & 1.5 \\
\hline
\end{tabular}

Table 7: Sale prices, backlog costs, holding costs and rejecting costs $\left(€ / \mathrm{m}^{2}\right)$

\begin{tabular}{|l|l|l|l|l|}
\hline $\begin{array}{l}\text { Finished Goods/ } \\
\text { Classes of orders }\end{array}$ & FG1 & FG2 & FG3 & FG4 \\
\hline ORD A & 15 & 60 & 30 & 90 \\
\hline ORD B & 300 & 400 & 200 & 300 \\
\hline ORD C & 1,500 & 2,000 & 1,000 & 1,500 \\
\hline
\end{tabular}

Table 8: Characteristics of the generated customer order proposals $\left(\mathrm{m}^{2}\right)$.

\begin{tabular}{|c|c|c|c|}
\hline \multicolumn{2}{|c|}{ Capacity parameters } & \multicolumn{2}{|c|}{ FGs and product family parameters } \\
\hline $\operatorname{ctp}_{\text {It }}$ & $80 \mathrm{~h}$ & $c p_{\text {ilt }}$ & $5 € / \mathrm{m}^{2}$ \\
\hline ctphel ${ }_{\text {It }}$ & $5 \mathrm{~h}$ & csetupi $_{i l}$ & $€ 400$ \\
\hline$t f a b i_{i l}$ & $0.02 \mathrm{~h} / \mathrm{m}^{2}$ & csetupf $_{f l}$ & $€ 900$ \\
\hline tsetupi $_{i l}$ & $4 \mathrm{~h}$ & $\operatorname{Imini}_{i l}$ & $1,500 \mathrm{~m}^{2}$ \\
\hline tsetupf $_{f i}$ & $8 \mathrm{~h}$ & $\operatorname{Iminf}_{f l}$ & $3,000 \mathrm{~m}^{2}$ \\
\hline chelı & $60 € / \mathrm{h}$ & & \\
\hline
\end{tabular}

Table 9: Main ATP\&CTP-LHP model parameters. 
Different types of problems were generated with the above common data, defined by the following characteristics: the Supply Scenario-Availability Type-Execution mode- $\alpha_{P}$ value. In relation to the Supply Scenario, the following percentages of the total supply used to generate the MPS quantities were: lacking supply (between $75 \%$ and $85 \%$ of total demand), adjusted supply (between $95 \%$ and $105 \%$ of total demand) and excess supply (between $115 \%$ and $125 \%$ of total demand). To generate the MPS, each order line quantity was multiplied randomly by a percentage within the above range of percentages defined for each type of supply and randomly assigned to a production line and a time period $\mathrm{t}$ within the interval $\left[t=1, t=d d_{o}+\operatorname{Rmax}_{o}\right]$. This was done for all the order lines and order proposals of the data sets. Finally, the quantities generated in this way that had been assigned to the same FG, production line and time period were summed up to define the MPS per production line over all the time periods of the planning horizon. As regards availability type, the ATP\&CTP-LHP model can be run with and without CTP, and in five execution modes: Single-Order Processing (SOP), Batch-Order Processing (BOP) with batching interval in weeks $\mathrm{B}=1$ (BOP1), $\mathrm{B}=2$ (BOP2), $\mathrm{B}=4$ (BOP4), and a global one (GOP), which is the equivalent to a Batch Order with $B=8$. The ceramic company's usual OPP execution modes are SOP and BOP $(B=1)$. However, in these simulation runs, additional execution modes with wider batching intervals than the real ones were defined to validate the model by analysing its behaviour in different scenarios and gaining some insights into its computational efficiency.

Finally, eleven ATP-LHP consumption rules were implemented by assigning different weights to $\alpha_{P}$ from 0 to 1 , with increments of 0.1 and with setting $\alpha_{A T P}=1-\alpha_{P}$. The GOP mode was executed only with $\alpha_{P}=1$, which meant $3 * 4 * 11+3=135$ executions in all.

\subsection{Analysis and discussion of the results}

The experiments were programmed in JAVA with the Eclipse platform v3.7.0. The mathematical programming model was also programmed in JAVA by using the Gurobi libraries (gurobi.jar). The solver was Gurobi v4.6. To check that the ATP\&CTP-LHP model had been appropriately programmed in JAVA, a comparison of its results with those obtained for the same model using the MPL language v4.2 was made. Experiments were conducted on a PC, whose processor was an Intel (R) Core(TM) i5-2410M CPU @ $2.30 \mathrm{GHz}$, with an installed memory of $4.00 \mathrm{~GB}$ and an operative system of 64 bits. 
The following paragraphs firstly check model validity and then analyse the impact of the ATP-LHP consumption rules on the global profit made throughout the horizon. Finally, some managerial insights are provided.

\subsubsection{Model Validation}

Tables 10 and 11 show the total profits $\left(\mathrm{Z}_{\mathrm{P}}\right)$ obtained during the OPP only with ATPLHP and ATP\&CTP-LHP, respectively. The total profits $\left(Z_{P}\right)$ for the non-GOP modes were obtained by summing the profits made with the committed orders for each OPP execution throughout the 8-period simulation horizon. This allowed a comparison to be made of the GOP mode with the non-GOP ones. In these tables, the bold numbers in the rows for each Supply Scenario represent the mean value of the different execution modes for that scenario and the corresponding $\alpha_{\mathrm{P}}$-value.

As observed in Table 10, the bigger the availability quantities, the more profits were made because more order proposals were promised. Therefore, the fewer the profits made for lacking supply, the higher the profits made for excess supply. The difference between the profits for each supply scenario was smaller when CTP-LHP was considered (Table 11) because, if there was not enough ATP-LHP, further lots could be scheduled in the master plan to commit any order not previously committed. For the ATP\&CTP-LHP cases and for all the supply scenarios, the model was almost always able to commit all the 100 customer order proposals. The difference in profits made among the different supply scenarios for ATP\&CTP-LHP stemmed from the setup and production costs and the delayed orders. These costs were higher for lacking supply than adjusted and excess supply because further production quantities also needed to be programmed to commit the same customer orders.

\begin{tabular}{|c|c|c|c|c|c|c|c|c|c|c|c|}
\hline $\begin{array}{l}\text { PROFIT (ATP- } \\
\text { LHP)/ } \alpha p\end{array}$ & 0 & 0,1 & 0,2 & 0,3 & 0,4 & 0,5 & 0,6 & 0,7 & 0,8 & 0,9 & 1 \\
\hline Lacking Supply & 1459927,47 & 1465831,05 & 1463004,88 & 1462695,35 & 1466379,87 & 1455767,00 & 1446445,73 & 1455466,36 & 1440703,35 & 1444846,99 & 1444640,14 \\
\hline SOP & 1429847,50 & 14466631,94 & 1447474,01 & 1447439,30 & 1427611,70 & 1415806,10 & 1388743,86 & 1388657,36 & 1388656,58 & 1388649,94 & 1394700,08 \\
\hline BOP1 & 1435478,13 & 1446091,20 & 1446278,99 & 1438199,07 & 1468058,79 & 1431139,42 & 1431306,09 & 1459746,45 & 1416337,95 & 1428538,05 & 1433210,31 \\
\hline BOP2 & 1481528,94 & 1475897,83 & 1475052,96 & 1476236,90 & 1477606,13 & 1484067,23 & 1477142,25 & 1482244,67 & 1475206,11 & 1478640,60 & 1441100,39 \\
\hline BOP4 & 1492855,32 & 1494703,22 & 1483213,58 & 1488906,14 & 1492242,85 & 1492055,26 & 1488590,71 & 1491216,95 & 1482612,78 & 1483559,38 & 1457522,01 \\
\hline GOP & & & & & & & & & & & 1496667,92 \\
\hline Adjusted Supply & 1849918,46 & 1865496,14 & 1848426,00 & 1856040,42 & 1858877,37 & 1862731,72 & 1854088,60 & 1834524,26 & 1840146,75 & 1828192,14 & 1844464,70 \\
\hline SOP & 1818016,74 & 1822088,44 & 1779669,73 & 1807149,82 & 1793357,31 & 1807545,49 & 1789858,24 & 1756309,03 & 1756309,03 & 1776109,75 & 1776113,64 \\
\hline BOP1 & 1818448,41 & 1870692,89 & 1846177,16 & 1848098,59 & 1877760,61 & 1877332,74 & 1848882,41 & 1808231,88 & 1832378,75 & 1790193,71 & 1808649,96 \\
\hline BOP2 & 1879150,51 & 1878353,90 & 1877003,52 & 1877032,36 & 1877247,82 & 1878923,99 & 1887966,09 & 1885696,36 & 1885547,71 & 1862028,03 & 1870177,93 \\
\hline BOP4 & 1884058,17 & 1890849,35 & 1890853,60 & 1891880,91 & 1887143,73 & 1887124,65 & 1889647,65 & 1887859,76 & 1886351,52 & 1884437,08 & 1870191,30 \\
\hline GOP & & & & & & & & & & & 1897190,66 \\
\hline Excess Supply & 1958110,98 & 1961235,98 & 1946568,21 & 1946905,25 & 1947072,17 & 1947378,95 & 1947683,61 & 1947778,62 & 1947962,21 & 1948550,45 & 1964336,37 \\
\hline SOP & 1958943,75 & 1962163,25 & 1902451,46 & 1902605,22 & 1902926,32 & 1903321,00 & 1903718,08 & 1903782,95 & 1903761,89 & 1903889,71 & $\overline{~ 1964060,92}$ \\
\hline BOP1 & 1957274,36 & 1960542,57 & 1961448,25 & 1961660,08 & 1961893,64 & 1962117,38 & 1962760,63 & 1962758,92 & 1962759,53 & 1963978,59 & 1964309,76 \\
\hline BOP2 & 1958375,33 & 1960773,39 & 1960888,91 & 1961896,96 & 1961936,84 & 1961898,77 & 1962082,27 & 1962434,85 & 1962876,47 & 1963328,45 & 1964304,51 \\
\hline BOP4 & 1957850,49 & 1961464,70 & 1961484,21 & 1961458,74 & 1961531,87 & 1962178,66 & 1962173,46 & 1962137,76 & 1962450,94 & 1963005,07 & 1964437,57 \\
\hline GOP & & & & & & & & & & & 1964569,09 \\
\hline
\end{tabular}

Table 10. Total profits $\left(\mathrm{Z}_{\mathrm{P}}\right)$ made only with ATP-LHP $(€)$ for the whole simulation horizon 


\begin{tabular}{|c|c|c|c|c|c|c|c|c|c|c|c|}
\hline $\begin{array}{l}\text { PROFIT (ATP\&CTP- } \\
\text { LHP)/ } \alpha p\end{array}$ & 0 & 0,1 & 0,2 & 0,3 & 0,4 & 0,5 & 0,6 & 0,7 & 0,8 & 0,9 & 1 \\
\hline Lacking Supply & 1770497,22 & 1809588,53 & 1811301,66 & 1811270,56 & 1812129,04 & 1811790,66 & 1811470,58 & 1811548,79 & 1811652,70 & 1811443,43 & 1812898,44 \\
\hline SOP & 1755833,77 & 1807890,28 & 1809424,93 & 1809165,03 & 1808602,33 & 1807296,48 & 1804984,66 & 1804289,62 & 1805287,86 & 1804859,26 & 1805050,71 \\
\hline BOP1 & 1772470,05 & 1803514,42 & 1806931,87 & 1808863,41 & 1810595,70 & 1812875,19 & 1811718,26 & 1813043,04 & 1811185,24 & 1809889,09 & 1811185,99 \\
\hline BOP2 & 1778408,11 & 1814172,00 & 1811970,86 & 1812390,68 & 1813149,77 & 1813234,54 & 1812844,01 & 1812532,94 & 1813437,03 & 1814107,82 & 1812437,76 \\
\hline BOP4 & 1775276,96 & 1812777,40 & 1816879,00 & 1814663,13 & 1816168,37 & 1813756,45 & 1816335,40 & 1816329,56 & 1816700,68 & 1816917,54 & 1815554,76 \\
\hline GOP & & & & & & & & & & & 1820262,96 \\
\hline Adjusted Supply & 1916942,94 & 1939210,84 & 1940508,80 & 1939651,29 & 1939860,01 & 1939109,31 & 1937747,84 & 1935804,23 & 1934356,63 & 1929778,21 & 1932066,03 \\
\hline SOP & 1895554,57 & 1932463,22 & 1937077,36 & 1933588,74 & 1933883,00 & 1930961,57 & 1925544,24 & 1920019,72 & 1916209,54 & 1916258,54 & 1914486,15 \\
\hline BOP1 & 1927939,13 & 1939240,77 & 1939731,20 & 1939861,12 & 1940685,54 & 1940727,37 & 1940482,45 & 1937888,21 & 1936654,87 & 1923469,89 & 1927554,47 \\
\hline BOP2 & 1919919,30 & 1942022,95 & 1942003,39 & 1942174,42 & 1941758,84 & 1941784,61 & 1942071,66 & 1942205,10 & 1941863,00 & 1937232,73 & 1935523,12 \\
\hline BOP4 & 1924358,75 & 1943116,43 & 1943223,23 & 1942980,88 & 1943112,66 & 1942963,70 & 1942893,01 & 1943103,91 & 1942699,11 & 1942151,68 & 1939383,53 \\
\hline GOP & & & & & & & & & & & 1943382,89 \\
\hline Excess Supply & 1908702,60 & 1937834,32 & 1954944,18 & 1959506,64 & 1959416,79 & 1960103,97 & 1960695,16 & 1960789,48 & 1961090,34 & 1961883,86 & 1964362,68 \\
\hline SOP & 1894020,74 & 1960173,62 & 1954451,60 & 1955085,64 & 1955761,09 & 1957142,31 & 1957161,01 & 1956997,12 & 1957055,23 & 1957332,34 & 1964060,92 \\
\hline BOP1 & 1865654,89 & 1950354,98 & 1960469,85 & 1960378,41 & 1960171,49 & 1959888,54 & 1961864,65 & 1962142,88 & 1962895,68 & 1963909,54 & 1964309,43 \\
\hline BOP2 & 1926600,40 & 1905113,59 & 1944683,03 & 1961182,24 & 1960242,01 & 1961246,27 & 1961618,14 & 1962006,39 & 1962119,55 & 1963303,36 & 1964442,17 \\
\hline BOP4 & 1948534,38 & 1935695,11 & 1960172,26 & 1961380,29 & 1961492,57 & 1962138,74 & 1962136,84 & 1962011,53 & 1962290,89 & 1962990,22 & 1964469,78 \\
\hline GOP & & & & & & & & & & & 1964531,09 \\
\hline
\end{tabular}

Table 11. Total profits $\left(\mathrm{Z}_{\mathrm{P}}\right)$ made with ATP\&CTP-LHP $(€)$ for the whole simulation horizon.

As regards the execution mode, the obtained results were coherent with those reported in the literature: the wider the batching interval, the more profits made. Consequently, for all the supply scenarios, the worst results were obtained for the SOP execution mode. For the BOP mode, profits improved as the batching interval increased; i.e. in general, profits $(\mathrm{BOP} 1)<=\operatorname{profits}(\mathrm{BOP} 2)<=\operatorname{profits}(\mathrm{BOP} 4)$. Obviously, the best profit results were obtained for the GOP execution mode and $\alpha_{P}=1$. The obtained results were coherent with those expected, which meant that the proposed model was internally valid.

\subsubsection{Impact of the ATP-LHP consumption rules}

In order to better analyse the impact of the different consumption rules $\left(\alpha_{P}<1\right)$ on profits in comparison to $\alpha_{P}=1$, the deviation among them was calculated for the ATP-LHP and ATP\&CTP-LHP cases in Tables 12 and 13, respectively. If we denoted Supply Scenario as $S S$, Available Type as $A T$ and Execution Mode as EM, the formula to calculate the deviation, as a percentage, between $\alpha_{P}<1$ and $\alpha_{P}=1$ for the same SS, AT and EM was (40). Therefore, a positive deviation value indicated that the corresponding ATP-LHP consumption rule made more profits compared when considering only $Z_{P}$ in the objective function, while a negative value indicated the opposite.

$\operatorname{Deviation}\left(S S, A T, E M, \alpha_{P}<1\right)=\frac{\operatorname{Profit}\left(S S, A T, E M, \alpha_{P}<1\right)-\operatorname{Profit}\left(S S, A T, E M, \alpha_{P}=1\right)}{\operatorname{Profit}\left(S S, A T, E M, \alpha_{P}=1\right)} \bullet 100$

As Table 11 shows, for the data set used in these experiments, when considering not only the objective of maximizing profits, but also the ATP-LHP consumption rules $\left(\alpha_{P}<1\right)$, 
the ATP case usually resulted in more profits for lacking and adjusted supply. Conversely with excess supply, it was better to consider only the typical objective of maximising profits when committing orders. In general terms, the scarcer supply was (lacking supply), the more beneficial was the impact of implementing the ATP-LHP consumption rule of reserving requested order quantities from the most adjusted ATP-LHP. This consumption rule also performed better for the SOP execution mode. In general, better results were obtained when defining a low $\alpha_{P}$ value: thus: $0<=\alpha_{P}<=0.6$.

Considering the consumption ATP-LHP rule in the objective function if ATP\&CTPLHP existed gave worse results than when contemplating only ATP-LHP (Table 13). Moreover, worse results were obtained for ATP\&CTP-LHP for excess supply. In this case, the best results were achieved for adjusted supply, perhaps because this adjusted supply scenario was similar to considering only ATP-LHP. Indeed, for adjusted supply when contemplating the ATP-LHP consumption rule provided better results for all the $\alpha_{P}$ between $[0.1,0.8]$ compared to $\alpha_{P}=1$. Furthermore, the improved profits made thanks to the ATP-LHP consumption rules further increased as the batching interval narrowed, and the best improvement was accomplished for the SOP execution mode. For lacking supply, the consumption rules almost always provided better results for the SOP execution mode, while the results obtained when considering the consumption rules were similar to those obtained when contemplating only maximising profits for other execution modes.

\begin{tabular}{|c|c|c|c|c|c|c|c|c|c|c|c|}
\hline DEVIATION (ATP-LHP)/ $\alpha p$ & 0 & 0,1 & 0,2 & 0,3 & 0,4 & 0,5 & 0,6 & 0,7 & 0,8 & 0,9 & 1 \\
\hline \multicolumn{12}{|l|}{ Lacking Supply } \\
\hline SOP & $2,52 \%$ & $3,72 \%$ & $3,78 \%$ & $3,78 \%$ & $2,36 \%$ & $1,51 \%$ & $-0,43 \%$ & $-0,43 \%$ & $-0,43 \%$ & $-0,43 \%$ & $0,00 \%$ \\
\hline BOP1 & $0,16 \%$ & $0,90 \%$ & $0,91 \%$ & $0,35 \%$ & $2,43 \%$ & $-0,14 \%$ & $-0,13 \%$ & $1,85 \%$ & $-1,18 \%$ & $-0,33 \%$ & $0,00 \%$ \\
\hline BOP2 & $2,81 \%$ & $2,42 \%$ & $2,36 \%$ & $2,44 \%$ & $2,53 \%$ & $2,98 \%$ & $2,50 \%$ & $2,86 \%$ & $2,37 \%$ & $2,61 \%$ & $0,00 \%$ \\
\hline BOP4 & $2,42 \%$ & $2,55 \%$ & $1,76 \%$ & $2,15 \%$ & $2,38 \%$ & $2,37 \%$ & $2,13 \%$ & $2,31 \%$ & $1,72 \%$ & $1,79 \%$ & $0,00 \%$ \\
\hline \multicolumn{12}{|l|}{ Adjusted Supply } \\
\hline SOP & $2,36 \%$ & $2,59 \%$ & $0,20 \%$ & $1,75 \%$ & $0,97 \%$ & $1,77 \%$ & $0,77 \%$ & $-1,12 \%$ & $-1,12 \%$ & $0,00 \%$ & $0,00 \%$ \\
\hline BOP1 & $0,54 \%$ & $3,43 \%$ & $2,08 \%$ & $2,18 \%$ & $3,82 \%$ & $3,80 \%$ & $2,22 \%$ & $-0,02 \%$ & $1,31 \%$ & $-1,02 \%$ & $0,00 \%$ \\
\hline BOP2 & $0,48 \%$ & $0,44 \%$ & $0,37 \%$ & $0,37 \%$ & $0,38 \%$ & $0,47 \%$ & $0,95 \%$ & $0,83 \%$ & $0,82 \%$ & $-0,44 \%$ & $0,00 \%$ \\
\hline BOP4 & $0,74 \%$ & $1,11 \%$ & $1,11 \%$ & $1,16 \%$ & $0,91 \%$ & $0,91 \%$ & $1,04 \%$ & $0,95 \%$ & $0,86 \%$ & $0,76 \%$ & $0,00 \%$ \\
\hline \multicolumn{12}{|l|}{ Excess Supply } \\
\hline SOP & $-0,26 \%$ & $-0,10 \%$ & $-3,14 \%$ & $-3,13 \%$ & $-3,11 \%$ & $-3,09 \%$ & $-3,07 \%$ & $-3,07 \%$ & $-3,07 \%$ & $-3,06 \%$ & $0,00 \%$ \\
\hline BOP1 & $-0,36 \%$ & $-0,19 \%$ & $-0,15 \%$ & $-0,14 \%$ & $-0,12 \%$ & $-0,11 \%$ & $-0,08 \%$ & $-0,08 \%$ & $-0,08 \%$ & $-0,02 \%$ & $0,00 \%$ \\
\hline BOP2 & $-0,30 \%$ & $-0,18 \%$ & $-0,17 \%$ & $-0,12 \%$ & $-0,12 \%$ & $-0,12 \%$ & $-0,11 \%$ & $-0,10 \%$ & $-0,07 \%$ & $-0,05 \%$ & $0,00 \%$ \\
\hline BOP4 & $-0,34 \%$ & $-0,15 \%$ & $-0,15 \%$ & $-0,15 \%$ & $-0,15 \%$ & $-0,12 \%$ & $-0,12 \%$ & $-0,12 \%$ & $-0,10 \%$ & $-0,07 \%$ & $0,00 \%$ \\
\hline
\end{tabular}

Table 12. Deviation (\%) from the profits made by allocating rule $\left(\alpha_{\mathrm{P}}=1\right)$ only with ATP-LHP 


\begin{tabular}{|c|c|c|c|c|c|c|c|c|c|c|c|}
\hline $\begin{array}{l}\text { DEVIATION } \\
\text { (ATP\&CTP-LHP)/ } \alpha p\end{array}$ & 0 & 0,1 & 0,2 & 0,3 & 0,4 & 0,5 & 0,6 & 0,7 & 0,8 & 0,9 & 1 \\
\hline \multicolumn{12}{|l|}{ Lacking Supply } \\
\hline SOP & $-2,73 \%$ & $0,16 \%$ & $0,24 \%$ & $0,23 \%$ & $0,20 \%$ & $0,12 \%$ & $0,00 \%$ & $-0,04 \%$ & $0,01 \%$ & $-0,01 \%$ & $0,00 \%$ \\
\hline BOP1 & $-2,14 \%$ & $-0,42 \%$ & $-0,24 \%$ & $-0,13 \%$ & $-0,03 \%$ & $0,09 \%$ & $0,03 \%$ & $0,10 \%$ & $0,00 \%$ & $-0,07 \%$ & $0,00 \%$ \\
\hline BOP2 & $-1,88 \%$ & $0,10 \%$ & $-0,03 \%$ & $0,00 \%$ & $0,04 \%$ & $0,04 \%$ & $0,02 \%$ & $0,01 \%$ & $0,06 \%$ & $0,09 \%$ & $0,00 \%$ \\
\hline BOP4 & $-2,22 \%$ & $-0,15 \%$ & $0,07 \%$ & $-0,05 \%$ & $0,03 \%$ & $-0,10 \%$ & $0,04 \%$ & $0,04 \%$ & $0,06 \%$ & $0,08 \%$ & $0,00 \%$ \\
\hline \multicolumn{12}{|l|}{ Adjusted Supply } \\
\hline SOP & $-0,99 \%$ & $0,94 \%$ & $1,18 \%$ & $1,00 \%$ & $1,01 \%$ & $0,86 \%$ & $0,58 \%$ & $0,29 \%$ & $0,09 \%$ & $0,09 \%$ & $0,00 \%$ \\
\hline BOP1 & $0,02 \%$ & $0,61 \%$ & $0,63 \%$ & $0,64 \%$ & $0,68 \%$ & $0,68 \%$ & $0,67 \%$ & $0,54 \%$ & $0,47 \%$ & $-0,21 \%$ & $0,00 \%$ \\
\hline BOP2 & $-0,81 \%$ & $0,34 \%$ & $0,34 \%$ & $0,34 \%$ & $0,32 \%$ & $0,32 \%$ & $0,34 \%$ & $0,35 \%$ & $0,33 \%$ & $0,09 \%$ & $0,00 \%$ \\
\hline BOP4 & $-0,78 \%$ & $0,19 \%$ & $0,20 \%$ & $0,19 \%$ & $0,19 \%$ & $0,19 \%$ & $0,18 \%$ & $0,19 \%$ & $0,17 \%$ & $0,14 \%$ & $0,00 \%$ \\
\hline \multicolumn{12}{|l|}{ ExcessSupply } \\
\hline SOP & $-3,57 \%$ & $-0,20 \%$ & $-0,49 \%$ & $-0,46 \%$ & $-0,42 \%$ & $-0,35 \%$ & $-0,35 \%$ & $-0,36 \%$ & $-0,36 \%$ & $-0,34 \%$ & $0,00 \%$ \\
\hline BOP1 & $-5,02 \%$ & $-0,71 \%$ & $-0,20 \%$ & $-0,20 \%$ & $-0,21 \%$ & $-0,23 \%$ & $-0,12 \%$ & $-0,11 \%$ & $-0,07 \%$ & $-0,02 \%$ & $0,00 \%$ \\
\hline BOP2 & $-1,93 \%$ & $-3,02 \%$ & $-1,01 \%$ & $-0,17 \%$ & $-0,21 \%$ & $-0,16 \%$ & $-0,14 \%$ & $-0,12 \%$ & $-0,12 \%$ & $-0,06 \%$ & $0,00 \%$ \\
\hline BOP4 & $-0,81 \%$ & $-1,47 \%$ & $-0,22 \%$ & $-0,16 \%$ & $-0,15 \%$ & $-0,12 \%$ & $-0,12 \%$ & $-0,13 \%$ & $-0,11 \%$ & $-0,08 \%$ & $0,00 \%$ \\
\hline
\end{tabular}

Table 13. Deviation $(\%)$ from the profits made by the allocation rule $\left(\alpha_{P}=1\right)$ with ATP\&CTPLHP

\subsubsection{Managerial insights}

Several potential benefits can be obtained by using the proposed decision support tool. One of its main advantages is related to the quality of the obtained solutions: the model provides the decision maker with information about which orders can be accepted/rejected that optimise the pursued objectives. For accepted orders, the optimal ATP-LHP assignation to the customer order lines requesting MTS products is also provided. For the MTS products requested with not enough ATP-LHP and also for MTO products, the model provides the new quantities or lots to be produced, and the extra capacity required, with savings in setups. Simultaneously considering the required capacity of MTS and MTO products provides a better use of common resources than when doing so sequentially or independently. It also allows customers to be provided with more reliable due dates than those consisting in a fixed lead time. All this by minimizing the operating costs, maximizing the customer service level even reducing stocks and their risks of obsolescence because of an optimal ATP-LHP assignment to orders and use of CTP-LHP.

The model also provides unmet customer orders, for which managers can use the model to renegotiate conditions with customers. For these orders, it is possible to obtain alternatives due dates by redefining its maximum delay in such a way that $\operatorname{rmax}_{o}=T$ - $d d_{o}$ (being $\mathrm{T}$ the planning horizon) and its backorder cost. The higher the backorder cost $\left(b_{o}\right)$ assigned to the order, the closer the policy will come to serve the order as soon as possible. With this data, 
the model can be solved again and the alternative due dates can be used during the renegotiation process with customers.

If supply is short, it seems reasonable to distinguish between more important customers/orders. Assigning a different priority to customers/orders can be implemented into the model through higher penalty costs of delaying/rejecting these orders, or also by setting their allowed delay at zero. If possible, partial deliveries of order lines can be managed by splitting the original customer order into as many orders as its number of order lines.

Due to LHP, the possibilities of serving orders from different subtypes of the same product exponentially grow. Furthermore, the homogeneity requirement and the high volume of orders to be promised, each one composed of multiple order lines, increase the problem complexity. For this reason, obtaining the optimal solution, and even a feasible one, becomes a very complicated and time-consuming task. Based on the computation times in Table 14, it is easy to observe the substantial savings made in time that using the model entails, especially in the BOP1 mode. The computation times for the execution modes with longer batching intervals increased. Longer computation times were generally required for the lack-of-supply scenario compared to other supply scenarios. However, for execution modes SOP, BOP1 and BOP2, the shorter computation times allowed an immediate answer to be given to customers by a medium-size company. The possibility of solve the model in different execution modes, provided the company with an opportunity to assess the trade-off between shorter customer response times and reduced profit. Furthermore, for those companies obliged to provide an on-line answer to customers (the SOP mode), they can combine the use of the model in the batch order to reallocate already promised orders during a given period of time to available quantities, which sure improves previous assignments.

\begin{tabular}{|c|c|c|c|c|c|c|}
\hline \multirow{2}{*}{$\begin{array}{l}\text { Supply/ } \\
\text { Mode }\end{array}$} & \multicolumn{3}{|c|}{ ATP-LHP } & \multicolumn{3}{|c|}{ ATP\&CTP-LHP } \\
\hline & Lacking & Adjusted & Excess & Lacking & Adjusted & Excess \\
\hline SOP & 0,04 & 0,04 & 0,04 & 0,04 & 0,05 & 0,04 \\
\hline BOP1 & 0,13 & 0,13 & 0,13 & 1,07 & 0,36 & 0,43 \\
\hline BOP2 & 0,57 & 0,63 & 9,94 & 85,80 & 10,06 & 5,82 \\
\hline BOP4 & 136,26 & 111,28 & 133,44 & 133,98 & 144,97 & 139,06 \\
\hline GOP & 2501,47 & 2501,42 & 4,53 & 2501,70 & 1105,22 & 14,24 \\
\hline
\end{tabular}

Table 14. Mean computation times (s) for optimally solving the ATP\&CTP-LHP model

Finally, the results that derive from the simulation runs show that correctly assigning weights to define the consumption ATP-LHP rules $\left(\alpha_{\mathrm{ATP}}\right)$ can improve the global profit made for a whole horizon in a dynamic environment in some supply scenarios (lacking and adjusted) and the OPP execution modes versus only considering the typical profits 
maximisation. These results are very valuable if we consider that companies tend to work according to an adjusted supply (lean) scenario. Consumption rules help to reduce one of the main problems in LHP sectors: their high volume of fragmented stock and its high risk of becoming obsolescent.

\section{Conclusions and future research lines}

Presence of LHP in manufacturing systems impacts the OPP and leads to a new problem with particular characteristics. LHP complicates the OPP by making it difficult to find not only an optimal solution, but also a feasible one. In such contexts, developing mathematical programming models is useful. In this paper, a mathematical programming model (ATP\&CTP-LHP) is developed to support OPP decision making in mixed MTS-MTO manufacturing systems with LHP that not only takes the MPS into account through ATP-LHP quantities, but also integrates some of its aspects by contemplating CTP-LHP.

To promise orders with customers, the ATP\&CTP-LHP model computes the so-called ATP-LHP. ATP-LHP derives from the on-hand inventory and is expressed in terms of the subtypes of the same FG. The discrete ATP-LHP quantities that derive from the master plan are expressed in terms of $\mathrm{FG}$, resources and time periods to anticipate the planned homogenous quantities of subtypes in the future. If there is not enough ATP-LHP to commit some customer orders of MTS-Products or MTO-Products, additional FG quantities can be produced if there is enough normal and extra remaining capacity (CTP-LHP). The aim of anticipating future homogeneous quantities implies incorporating some typical features of more detailed Finite Capacity Scheduling models; e.g., lot-sizing, loading and FG and family setups (Steger-Jensen \& Svensson, 2004). The CTP-LHP part of the model solves the capacitated lot-sizing and loading problem (Alemany, Boj, Mula \& Lario, 2010) with setups considerations, minimum lot sizes, and setup savings of families and/or FG quantities, whenever possible.

Accumulating discrete ATP-LHP quantities between periods and/or resources to serve the same customer order is not allowed because they are probably not homogeneous. This aspect in LHP contexts means that the final choice affects future commitments when different possibilities exist to reserve the homogeneous ATP-LHP quantities to be committed and ordered. To help guide the final choice, a new objective function has been defined apart from the traditional one of maximising profits. This new objective aims to reserve FG from the most adjusted ATP-LHP quantity. By varying the weights assigned to each objective, 
different ATP-LHP consumption rules have been implemented that provide several solutions. In order to validate the proposed model and to evaluate if consumption rules affect the obtained results, different types of problems for the realistic data of a Spanish ceramic company have been generated, defined by the following characteristics: Supply scenarioAvailability Type-Execution mode- $\alpha_{P}$ value.

To apply it to the Spanish ceramic tile SC under study, it can be concluded that implementing ATP-LHP consumption rules $\left(\alpha_{P}<1\right)$ according to adjusted supply mostly leads to better results than exclusively maximising profits $\left(\alpha_{P}=1\right)$ for ATP-LHP and ATP\&CTPLHP. If supply is lacking, the improvement made when considering ATP-LHP rules is substantial, but only when considering ATP-LHP, which is not true for ATP\&CTP-LHP. Moreover, considering consumption rules in the objective function for the SOP execution mode usually provides better results than contemplating only maximising profits. This is because implementing consumption rules can be considered a "looking ahead" rule that anticipates the likelihood of serving future incoming orders, and therefore reducing the myopic nature of the SOP execution mode. Only for excess supply does considering maximising profits alone provide better results. However, efficient SCs should work according to adjusted supply.

Hence we can state that for the specific SC under study that, based on the obtained results, considering both consumption rules and profit maximisation usually provides better results. In short, when contemplating the consumption rules in the objective function, the system attempt to improve the possibility of serving future incoming orders. At this point it is important to highlight that the conclusions we draw are restricted to the case studied herein and cannot be directly extrapolated to other cases. However, we can draw these valid conclusions: 1) the validity of the proposed model has been proven for handling the OPP in a hybrid MTS-MTO context with LHP; 2) in certain cases, the ATP-LHP consumption rules help improve global profits for the whole OPP horizon; 3) the experimental design methodology reported herein can be replicated by decision makers in any situation to select the most suitable weight of each objective that results in a better OPP performance under a rolling horizon scheme.

In this context, future research lines to complement this work are devised. Firstly, the experimental design implemented herein can be used as a configuration process to adjust consumption rules to other particular companies with LHP. In doing so, the development of a Model-Based Decision Support System to provide decision makers with simulation 
capabilities to choose the most satisfactory model configuration and solution to be implemented could be very interesting. Secondly, the implementation of ATP-LHP assignation and consumption rules by OF2 can be viewed to similarly solve a 0-1-multipleknapsack-problem in such a way that the unused spaces of knapsacks should be as low and as big as possible (i.e., the variance of the remaining unused ATP quantities is maximised). The comparison made between the results obtained by applying standard greedy heuristics for knapsack and bin packing problems with the ATP-LHP assignation rule implemented in an MILP model can be an interesting future work when only ATP-LHP quantities are considered. Thirdly, applying the model to real-size problems would require comparing between the solution times to optimality with customer response time requirements. For companies whose model's optimal solution time is longer the than the customer response time, resorting to heuristics or meta-heuristics could be necessary. In this case, readers are referred to Senvar, Turanoglu and Kahraman (2013) and to Grillo, Peidro, Alemany and Mula (2015). Finally, future work can be done to assess the global performance of the close integration of both the MPS and OPP, compared to other approaches that sequentially deal with ATP-LHP and CTP-LHP.

\section{References}

Alemany MME., Alarcón F, Ortiz A, Lario FC. Order promising process for extended collaborative selling chain. Prod. Plan. \& Control, 2008: 19 (2): 105-131.

Alemany M.M.E, Boj J.J, Mula J. M, Lario F.C. Mathematical programming model for centralised master planning in ceramic tile supply chains. Int. J. Prod. Res., 48 (17) (2010) 5053-5074.

Alemany MME, Ortiz A, Boza A, Fuertes-Miquel VS. A model-driven decision support system for reallocation of supply to orders under uncertainty in ceramic companies. Technol. Econ. Dev. Econ. ,2015: 21(4): 596-625.

Alemany MME, Grillo H, Ortiz A, Fuertes-Miquel VS.A fuzzy model for shortage planning under uncertainty due to lack of homogeneity in planned production lots. Appl. Math. Model., 2015: 39:4463-448.

Akkan C. Improving schedule stability in single-machine rescheduling for new operation insertion, Comput. \& Oper. Res., 2015: 64: 198-209. 
Brabazon PG, MacCarthy B. Fundamental behaviour of virtual-build-to order systems. Int. J. Prod. Econ., 2006: 104 (2): 514-524.

Brabazon PG, MacCarthyBL. On Markovian approximations for virtual build-to-order systems. J. Oper. Res., Soc., 2010: 61 (10), 1471-1484.

Cesaret B, Oğuz C, Sibel Salman F. A tabu search algorithm for order acceptance and scheduling. Comput. \& Oper. Res., 2012: 39 (6): 1197-1205

Christou IT, Ponis S. A hierarchical system for effective coordination of available-to-promise logic mechanisms. Int. J. Prod. Res., 2009: 47 (11): 3063-3078.

Dumetz L, Gaudreault J, Thomas A, Lehoux N. Evaluating order acceptance policies for divergent production systems with co-production, Int. J. Prod. Res., 2016,http://dx.doi.org/10.1080/00207543.2016.1193250

Fleischmann B, Meyr H, 2004. Customer orientation in advanced planning systems. In: H. Dyckhoff, R. Lackes and J. Reese, eds. Supply Chain Manag. Reverse Logist. Berlin: Springer, 2004: 298-322.

Fogarty DW, Blackstone JH, Hoffmann TR. Production and inventory management: Southwestern Publishing CO, 1991.

Framiñán JM, Leisten R. Available-to-promise (ATP) systems: a classification and framework for analysis. Int. J. Prod. Res., 2009: 48 (11): 3079-3103.

Grillo, H., Peidro, D., Alemany, M.M.E., Mula, J. Application of particle swarm optimisation with backward calculation to solve a fuzzy multi-objective supply chain master planning model. Int. J. Bio-Inspired Comput., 2015: 7, 157-169.

Grillo H, Alemany MME, Ortiz A. A review of mathematical models for supporting the order promising process under Lack of Homogeneity in Product and other sources of uncertainty. Comput.\& Ind. Eng., 2016: 91: 239-261

Grillo H, Alemany MME, Ortiz A., Fuertes-Miquel V.S., Mathematical modelling of the order-promising process for fruit supply chains considering the perishability and subtypes of products, Applied Mathematical Modelling, 2017:49:255-278.

Han G, Dong M, Liu S. Yield and allocation management in a continuous make-to-stock system with demand upgrade substitution, Int. J. Prod. Econ, 2014: 156: 124-131, http://dx.doi.org/10.1016/j.ijpe.2014.05.013.

Kalantari M, Rabbani M, Ebadian M. A decision support system for order acceptance/rejection in hybrid MTS/MTO production systems. Appl. Math. Model., 2011: 35 (3): 1363-1377. 
Kilger C, Meyr H. Demand Fulfilment and ATP. In: H. Stadtler and C. Kilger, eds. Supply Chain Management and Advanced Planning. Concepts, Models, Software, and Case Studies. Springer, 2008: 191-198.

Kilger C., Schneeweiss L. Demand fulfilment and ATP. In: H. Stadtler and C. Kilger, eds. Berlin: Springer, 2000:79-95.

Lin J.T., Hong I-H, Wu C-H, Wan K-S. A model for batch available-to-promise in order fulfillment processes for TFT-LCD production chains. Computers \& Industrial Engineering, 2010: 59(4), 720-729

Makatsoris Hc, Chang Ys, Richards Hd. Design of a distributed order promising system and environment for a globally dispersed supply chain. Int JComputerIntegrManuf, 2004: 17(8): 679-691.

Marler RT,Arora J, 2010. The weighted sum method for multi-objective optimization: new insights. Struct. \& Multidiscip.Optim., 2010: 41 (6): 853-862.

Meyr, H. Customer segmentation, allocation planning and order promising in make-to-stock production, OR Spectrum 31 (1) (2009) 229-256.

Okongwu U, Lauras M, Dupont L, Humez V. A decision support system for optimising theorder fulfilment process, Prod. Plan. \& Control, 2012: 23(8): 581-598, http://dx.doi.org/10.1080/09537287.2011.566230

Özdamar L,Birbil Şİ. Hybrid heuristics for the capacitated lot sizing and loading problem with setup times and overtime decisions. Eur. J. Oper. Res., 1998: 110 (3), 525-547

Quante R, Meyr H., Fleischmann M. Revenue management and demand fulfillment: matching applications, models, and software. OR Spectrum,2009: 31 (1): 31-62.

Robinson AG, Carlson RC. Dynamic order promising: real-time ATP. Int. J. Integr. Supply Manag., 2007: 3 (3), 283-301

Rom WO, Slotnick SA. Order acceptance using genetic algorithms. Comput. \&Oper. Res., 2009: 36(6): 1758-1767.

Senvar O, Turanoglu E, Kahraman C. Usage of metaheuristics in engineering: a literature review. Meta-Heuristics Optim. Algorithms Eng. Bus. Econ. Finance, 2013: 484-528.

Steger-Jensen K, Svensson C. Issues of mass customization and supporting IT-solutions. Comput. Ind., 2004: 54 (1): 83-103.

Volling T, Spengler T. Modeling and simulation of order-driven planning policies in build-toorder automobile production. Int. J. Prod. Econ., 2011: 131: 183-193. 
Volling T, Matzke A, Grunewald M, Spengler TS. Planning of capacities and orders in buildto-order automobile production: A review. Eur. J. Oper. Res., 2013: 224: 240-260

Zschorn L. An extended model of ATP to increase flexibility of delivery. Int. J. Computer Integr. Manuf., 2006:19 (5): 434-442. 


\begin{tabular}{|c|c|c|c|c|c|c|c|c|c|c|c|c|c|c|c|c|c|}
\hline \multirow[t]{2}{*}{$\begin{array}{l}\text { REF } \\
\text { ERE } \\
\text { NCE } \\
S\end{array}$} & \multirow[t]{2}{*}{$\begin{array}{l}\text { TYPE } \\
\text { OF } \\
\text { MODE } \\
\text { L/WO } \\
\text { RK } \\
\end{array}$} & \multicolumn{2}{|c|}{$\begin{array}{l}\text { HOMO } \\
\text { GENEI } \\
\text { TY } \\
\text { REQUI } \\
\text { RED } \\
\end{array}$} & \multicolumn{2}{|c|}{$\begin{array}{l}\text { TYPE OF } \\
\text { PRODUC } \\
\text { TS }\end{array}$} & \multicolumn{4}{|c|}{$\begin{array}{l}\text { AVAILABILIT } \\
\text { Y LEVELS }\end{array}$} & \multicolumn{2}{|c|}{$\begin{array}{l}\text { ATP\& CTP } \\
\text { AVAILABILIT } \\
\text { Y CHECK }\end{array}$} & \multicolumn{3}{|c|}{$\begin{array}{l}\text { CTP } \\
\text { MODELLING }\end{array}$} & \multicolumn{3}{|c|}{$\begin{array}{l}\text { MPS } \\
\text { MODIFICATI } \\
\text { ON }\end{array}$} \\
\hline & & $\begin{array}{l}\mathrm{YE} \\
\mathrm{S}\end{array}$ & $\begin{array}{l}\mathrm{N} \\
\mathrm{O}\end{array}$ & $\begin{array}{l}\text { MT } \\
\text { S/ } \\
\text { BT } \\
\text { S }\end{array}$ & $\begin{array}{l}\text { MT } \\
\text { O/ } \\
\text { BT } \\
\text { O }\end{array}$ & $\begin{array}{l}\text { A } \\
\text { T } \\
\text { P }\end{array}$ & $\begin{array}{l}\mathrm{C} \\
\mathrm{T} \\
\mathrm{P}\end{array}$ & $\begin{array}{l}\text { A } \\
T \\
P \\
- \\
L \\
H \\
P\end{array}$ & $\begin{array}{l}\text { C } \\
T \\
P \\
- \\
L \\
H \\
P\end{array}$ & $\begin{array}{l}\text { Sequen } \\
\text { tial/Ind } \\
\text { epend }\end{array}$ & $\begin{array}{l}\text { Jo } \\
\text { in } \\
\text { tl } \\
y\end{array}$ & $\begin{array}{l}\text { Ex } \\
\text { tra } \\
\text { ca } \\
\text { pa } \\
\text { cit } \\
y\end{array}$ & $\begin{array}{l}\text { Se } \\
\text { tu } \\
\text { ps }\end{array}$ & $\begin{array}{l}\mathrm{Mi} \\
\mathrm{ni} \\
\mathrm{mu} \\
\mathrm{m} \\
\text { Lot } \\
\mathrm{Siz} \\
\mathrm{e}\end{array}$ & $\begin{array}{l}\text { St } \\
\text { at } \\
\text { ic }\end{array}$ & $\begin{array}{l}\text { Dy } \\
\text { na } \\
\text { mi } \\
\text { c }\end{array}$ & $\begin{array}{l}\text { Exp } \\
\text { licit } \\
\text { ly } \\
\text { De } \\
\text { scri } \\
\text { be } \\
\text { d }\end{array}$ \\
\hline $\begin{array}{l}\text { Ale } \\
\text { man } \\
\text { y et } \\
\text { al. } \\
\text { (201 } \\
5) \\
\end{array}$ & MILP & $x$ & & $x$ & & & & $X$ & & & & & & & & & \\
\hline $\begin{array}{l}\text { Grill } \\
\text { o et } \\
\text { al. } \\
\text { (201 } \\
7)\end{array}$ & MILP & $x$ & & $x$ & & & & $x$ & & & $\gamma$ & & & & & & \\
\hline $\begin{array}{l}\text { Mak } \\
\text { atso } \\
\text { ris } \\
\text { et } \\
\text { al. } \\
\text { (200 } \\
\text { 4) }\end{array}$ & $\begin{array}{l}\text { Archite } \\
\text { cture }\end{array}$ & & $x$ & $x$ & & $x$ & $x$ & & 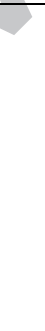 & $x$ & & & & & $x$ & & \\
\hline $\begin{array}{l}\text { Chri } \\
\text { stou } \\
\text { and } \\
\text { Poni } \\
\text { s } \\
\text { (200 } \\
\text { 9) }\end{array}$ & MILP & & $x$ & $x$ & & $x$ & $x$ & & & $x$ & & $x$ & & & $x$ & & \\
\hline $\begin{array}{l}\text { Bra } \\
\text { baz } \\
\text { on } \\
\text { and } \\
\text { Mac } \\
\text { Cart } \\
\text { hy } \\
\text { (200 } \\
\text { 6) }\end{array}$ & $\begin{array}{l}\text { Simula } \\
\text { tion }\end{array}$ & & $x$ & $x$ & & $x$ & $x$ & & & $x$ & & & & & & & \\
\hline $\begin{array}{l}\text { Bra } \\
\text { baz } \\
\text { on } \\
\text { and } \\
\text { Mac }\end{array}$ & $\begin{array}{l}\text { Marko } \\
\mathrm{v}\end{array}$ & & $x$ & $x$ & & $x$ & $x$ & & & $x$ & & & & & & & \\
\hline
\end{tabular}




\begin{tabular}{|c|c|c|c|c|c|c|c|c|c|c|c|c|c|c|c|c|c|}
\hline $\begin{array}{l}\text { Cart } \\
\text { hy } \\
(201 \\
0)\end{array}$ & & & & & & & & & & & & & & & & & \\
\hline $\begin{array}{l}\text { Robi } \\
\text { son } \\
\text { and } \\
\text { Carl } \\
\text { son } \\
\text { (200 } \\
7)\end{array}$ & MILP & & $x$ & $x$ & $\mathrm{x}$ & $x$ & $x$ & & & & $x$ & & & & 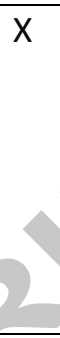 & & \\
\hline $\begin{array}{l}\text { Kala } \\
\text { ntar } \\
\text { i et } \\
\text { al. } \\
\text { (201 } \\
\text { 1) }\end{array}$ & $\begin{array}{l}\text { DSS/M } \\
\text { ILP }\end{array}$ & & $x$ & $x$ & $X$ & $x$ & $x$ & & & $x$ & & $x$ & & & $x$ & & \\
\hline $\begin{array}{l}\text { Du } \\
\text { met } \\
\text { z et } \\
\text { al. } \\
\text { (201 } \\
6 \text { ) }\end{array}$ & $\begin{array}{l}\text { Simula } \\
\text { tion }\end{array}$ & & $x$ & $x$ & $x$ & $x$ & $x$ & & & $x$ & & & & & & & \\
\hline $\begin{array}{l}\text { Volli } \\
\text { ng } \\
\text { et } \\
\text { al. } \\
\text { (201 } \\
\text { 3) }\end{array}$ & Review & & $x$ & $x$ & $\bar{x}$ & $\mathrm{X}$ & $x$ & & 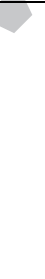 & $x$ & & & & & & & \\
\hline $\begin{array}{l}\text { Volli } \\
\text { ng } \\
\text { and } \\
\text { Spe } \\
\text { ngle } \\
\text { r } \\
\text { (201 } \\
\text { 1) }\end{array}$ & MILP & & $x$ & & $x$ & & $x$ & & & & & $x$ & & & & $x$ & $x$ \\
\hline $\begin{array}{l}\text { This } \\
\text { pap } \\
\text { er }\end{array}$ & $\begin{array}{l}\text { MILP/ } \\
\text { Metho } \\
\text { dology }\end{array}$ & $x$ & & $x$ & $x$ & & & $X$ & $\mathbf{X}$ & & $X$ & $x$ & $X$ & $x$ & & $x$ & $x$ \\
\hline
\end{tabular}


A decision support tool for the order promising process with product homogeneity requirements in hybrid Make To Stock and Make To Order environments. Application to a ceramic tile company

M.M.E Alemany, A. Ortiz, V.S. Fuertes-Miquel

Acknowledgements

This work was supported by the Spanish Ministry of Economy and Competitiveness with Grant DPI2011-23597 and the Polytechnic University of Valencia with Grant Ref. PAID-06$11 / 1840$. 


\section{Highlights}

TITLE: A decision support tool for the order promising process with product homogeneity requirements in hybrid Make-To-Stock and MakeTo-Order environments. Application to a ceramic tile company

- A novel MILP model for promising orders with homogeneity requirements is proposed.

- Homogeneous Available-To-Promise and Capable-To-Promise are simultaneously checked

- Master planning and order promising are more closely integrated into a single model.

- Different consumption rules of homogeneous Available-To-Promise are implemented.

- Results show that in certain scenarios, consumption rules improve the global profits. 